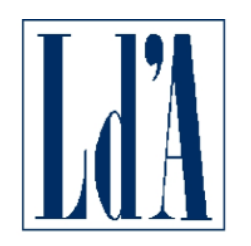

CENTRO STUDI LUCA D'AGLIANO

WWW.DAGLIANO.UNIMI.IT

\author{
CENTRO STUDI LUCA D'AGLIANO \\ DEVELOPMENT STUDIES WORKING PAPERS
}

N. 412

January 2017

Measuring Environmental Policy Stringency: Approaches, Validity, and Impact on Energy Efficiency

\author{
Marzio Galeotti* \\ Silvia Salini** \\ Elena Verdolini***
}

* Università degli studi di Milano, Centro Studi Luca D'Agliano, and IEFE-Bocconi ** Università degli Studi di Milano

*** Fondazione Eni Enrico Mattei and CMCC 


\title{
Measuring Environmental Policy Stringency: Approaches, Validity, and Impact on Energy Efficiency
}

\author{
Marzio Galeotti \\ Università degli studi di Milano, Centro Studi Luca D’Agliano, and IEFE-Bocconi \\ Silvia Salini \\ Università degli Studi di Milano \\ Elena Verdolini \\ Fondazione Eni Enrico Mattei and CMCC
}

This version: December 2015

\begin{abstract}
Proponents of the green growth strategy worldwide hold that reductions of harmful greenhouse gas emissions through environmental policy can be pursued together with increased growth and can result in higher competitiveness. Solid tests of this theory are impaired by the lack of appropriate empirical proxies for the commitment to, and stringency of, environmental policy. We contribute to the literature by: (1) computing different indicators of environmental policy stringency, both previously used in the literature and novel, (2) testing to what extent they convey similar insights through a comparison exercise, and (3) showing the implications of using one or the other methodology in an empirical application testing whether countries with more stringent environmental and energy policy have indeed shown historically higher degree of energy efficiency. The application is cast in an Energy Kuznets Curve framework. The analysis quite naturally carries over to the role of, more generally, economic policy.
\end{abstract}

Keywords: Energy policy, environmental policy, ranking, Energy Kuznets Curve JEL codes: Q58, O57, C33

This paper was prepared within the "Value Added in Motion (VAM)" project, funded by the Enel Foundation. We are grateful to Arik Levinson, Reyer Gerlagh, and Francesco Vona for comments on a previous version of the paper. E-mail addresses: marzio.galeotti@unimi.it (Marzio Galeotti), silvia.salini@unimi.it (Silvia Salini), elena.verdolini@feem.it (Elena Verdolini). 


\section{Introduction}

Assessing the effectiveness of economic policy is central to Economics. From monetary policy and financial regulation to wage policies and labor market regulation, from competition policy or welfare and poverty support intervention to energy regulation to environmental policies, the role of economic policy is pervasive. Notably, the effectiveness in reaching the desired goals is often, if not always, taken for granted.

Raising concerns about the impact of anthropogenic greenhouse gas emissions (GHG) have recently pushed more and more governments to take concrete mitigation actions. To this end, countries are implementing increasingly stringent environmental policies which are aimed at internalizing the social cost of pollution or, alternatively, at reducing the price wedge between clean and dirty technologies. This shift is however accompanied by rising concerns that increased environmental policy stringency may come at the expense of competitiveness and well-being, especially in light of the recent economic downturn.

Indeed, mainstream Economics holds that environmental policy represents an additional cost (burden) for firms, and this will necessarily harm their productivity and competitiveness. As an example, the so-called Pollution Haven Hypothesis postulates that increasing environmental standards will push polluting firms to relocate abroad, suggesting that this will likely harm the competitiveness and the welfare of citizens in countries with more stringent regulation (Tobey, 1990; Cole and Elliott, 2003; Levinson and Taylor, 2004).

Although many among researchers and policy makers hold that "you cannot have the cake and eat it, too", maintaining that environmental quality and increased competitiveness are conflicting policy goals, the recent policy discourse is centred on the possibility of setting the economy on a green growth path. Proponents of this strategy worldwide hold that fostering reductions of harmful greenhouse gas emissions through environmental policy can be pursued together with increased growth and can result in higher competitiveness (Jaffe et al., 1995). For instance, Porter (1991) and Porter and Van der Linde (1995) claimed that well-crafted and well-enforced environmental regulation would benefit both the environment and the firm. Supporters of this view argue that environmental policy stringency will not harm competitiveness, but will benefit firms through increased innovation activity and improved productivity (Gray and Shadbegian, 1993; Jaffe and Palmer, 1997; Lanoie et al., 2011; Ambec at al., 2013).

The debate on the impact of environmental policy on economic growth has important implications, but solid tests are impaired by the lack of appropriate empirical proxies for the commitment to, 
and stringency of, environmental policy. Most of the studies on the impact of environmental policy on growth, productivity, and trade-related variables present conflicting results. This is due to three main reasons: (i) they differ in the sample of sectors/countries considered, (ii) they apply different empirical approaches and methodologies, and, last but not least, (iii) they use different proxies for the stringency of environmental policy. Such diversity makes it very hard to draw definite conclusions on the role and effectiveness of environmental policy.

In this paper we conduct an empirical investigation of whether different policy indicators convey overlapping or complementary information. This is an important question, which has implications for the analysis of environmental policy impact on economic growth. If the different indicators proposed in the literature convey similar information, concerns about using one or the other indicator in empirical applications would be highly mitigated. Conversely, if, as we might expect, these indicators convey different and complementary information, benefits can in principle be drawn by building a more general indicator capturing information from each of the components.

We proceed in three steps. First, we compute several of the policy indicators suggested in the literature. These include emission-based indicators as well as composite policy indexes and information about environmental R\&D expenditures. Second, we compare them through a statistical analysis aimed to understand to what extent the various indicators convey similar/overlapping information. We concentrate on differences in average country rankings to show how the different indicators capture variations between countries. Third, we focus on differences in capturing within country variation. To this end, we use the policy indicators in an application to assess to what extent empirical results obtained in a panel setting are indicatordependent. Specifically, we test whether countries with more stringent environmental policy have indeed shown historically higher levels of energy efficiency. We carry out this analysis in an Energy Kuznets Curve framework using panel data for 19 OECD countries over the years 19952009.

The preliminary results emerging from the statistical analysis show that the various environmental policy proxies do not always convey the same information. Specifically, some indicators result in significantly different average country rankings within the sample. However, our empirical application shows that, notwithstanding these differences in explaining between countries variation, all indicators perform in a similar way in our empirical application. This suggests that within-country variation is similarly captured by all the indicators computed. 
The remainder of the paper is organized as follows. Section 2 reviews the methodologies used in the empirical literature to proxy for the stringency of environmental policy. Section 3 presents the indicators of environmental policy. Section 4 compares the various indicators. Section 5 uses these indicators in an empirical application to energy efficiency. Section 6 concludes.

\section{Environmental Policy Stringency: Measurement and Conceptual Issues}

Measuring environmental policy stringency is a very difficult task. Brunel and Levinson (2013) highlight the main challenges faced in any empirical analyses. First, countries can choose from a wide array of policy instruments to address climate and energy concerns. Each of these instruments is characterized by a different level of effectiveness, dynamic efficiency and political acceptability (Fisher and Newell, 2008). Hence, building a policy indicator requires facing this "multidimensionality" of a country's policy portfolio. Second, countries with worse pollution challenges might impose more stringent options. Not accounting for this would provide a biased indicator of environmental policy stringency. Third, some "initial condition" or some time varying characteristics, such as the industrial composition of the economy, the level of energy efficiency or the age of capital, might crucially affect the ability of countries to implement certain (lower cost) options. Finally, environmental policy is often endogenously determined. Notwithstanding these obstacles, several indicators have been proposed and applied in the literature. They can be grouped in four main categories: (a) pollution abatement effort, (b) direct assessments of regulations, (c) emission-based indexes, and (d) composite indicators. ${ }^{1}$

a) Variables measuring pollution abatement efforts. These include measures of both private and public effort. Pollution Abatement Costs and Expenditures (PACE) by private firms is among the most common indicators used. They are obtained from firm surveys. The main criticisms to such indicators are that they are subject to measurement errors, that they are potentially plagued with reverse causality issues, and that in the presence of market or behavioral failures they do not successfully measure the level of regulatory pressure (Berman and Bui, 2001). Measures of government efforts to control pollution include environmental R\&D expenditures, total revenue from environmental taxes and the implicit tax rate on energy. These indicators gauge the commitment of governments to devote public money to the support of pollution or emission control. However, since this is only an indirect measure of government effort, this proxy has been less and less used as other direct measures, such as emissions and cost data,

\footnotetext{
${ }^{1}$ Brunel and Levinson (2013) identify five categories, by splitting our first category into private efforts (PACE) and government R\&D efforts.
} 
have become available. Note that both types of proxies are generally characterized by very poor country coverage, as we will further discuss below.

b) Direct assessments of regulations. When dealing with very narrowly-focused research questions, researchers have often resorted to specific proxies for environmental policy stringency. This approach becomes increasingly difficult as the focus of analysis widens. For instance, finding good proxies based on direct assessment of regulation at the sector or country level is difficult due to multidimensionality and simultaneity. An alternative widely-used strategy in this category of proxies is to treat the US Clean Air Act as a natural experiment, since its standardized air quality limits (the NAAQS) address both problems above. Another example of a narrow regulation-based measure is the use of the lead content of gasoline as an indicator for overall environmental regulatory stringency.

c) Composite indexes. Some of the earliest examples of this type of indicator were based on simple indexes constructed from counts of regulations, non-governmental environmental organizations, international treaties signed, and similar variables. Another approach is to use statistical aggregation techniques, such as Principal Component Analysis, on a set of environmental policy indicators. More recently, approaches have been proposed to model environmental policy stringency as a latent variable, which we will discuss more in detail below.

d) Measures based on ambient pollution, emissions, or energy use. Some studies have turned the question on its head and used emissions, ambient pollution, or energy use as measures of stringency. Early attempts in this direction used information about the level of (or the change in) emissions and energy use at the country or sector level. However, both changes and levels can differ across countries for many reasons other than environmental policy stringency, such as for instance differences in industrial composition and in the degree of trade openness. Furthermore, emission- or energy use-based indicators are also likely to mirror changes other than in regulatory stringency, such as for example in factor prices. To overcome these shortcomings, Brunel and Levinson (2013) refine this approach and propose an indicator which is computed calculating the distance of each country from the sample average.

In this paper, we focus on three of the above categories, namely variables measuring pollution abatement effort, composite indicators and emission-based indicators. ${ }^{2}$ The first type of indicator has been widely used in the past (especially PACE), notwithstanding the scattered data coverage.

\footnotetext{
2 "Natural experiment" approaches are useful, but are hard to find in a cross-country setting.
} 
The second and the third types of indicators have recently become more and more popular due to increased data availability across a wide set of countries. Hence, these two types of indicators will be increasingly used in future assessments of the environmental policy impact on economic growth.

In the next section, we compute and compare several proxies which have been implemented in the past to measure environmental policy stringency. This represents to date the only attempt at comparatively assessing different options to measure environmental policy stringency.

\section{Data Sources, Indicators and Descriptive Statistics}

Focusing on three different types of environmental policy indicators necessarily requires selecting different datasets. We describe each indicator in detail below. Combining the data availability of the various indicators, we are able to create a sample of at most 19 OECD countries over the years 1995-2009. ${ }^{3}$ In order to make all indicators comparable in a straightforward way, we normalize them between 0 and 10 by applying the transformation: $I^{\mathrm{n}}=\left(\mathrm{I}-\mathrm{I}_{\min }\right) /\left(\mathrm{I}_{\max }-\mathrm{I}_{\min }\right)^{*} 10$, where $\mathrm{I}^{\mathrm{n}}$ is the normalized indicator, $I$ is the indicator under consideration, and $I_{\min }$ and $I_{\max }$ are the lowest and the highest values of the indicator in our sample. ${ }^{4}$ Country-level averages for the different indicators over the sample period are presented in Table 1. In the rest of this Section, we present and discuss each indicator and briefly comment on its time development for the countries in our sample. A comparison of the country rankings obtained from the average values of each indicator over the sample period is conducted in the next section. A comparison of the performance of several indicators in a panel setting is subsequently presented and discussed in Section 5 through an empirical application.

\subsection{Proxies for Pollution Abatement Effort}

We select four indicators that can be used to proxy for a country's pollution abatement efforts: PACE, energy R\&D budgets, the implicit tax rate on energy and total environmental tax revenues. The time profiles of all normalized indicators are presented in Figure 1 and descriptive Statistics are provided in Table 1. As already mentioned, information about all these indicators is missing for some countries in some years.

\footnotetext{
${ }^{3}$ The countries are Austria, Australia, Belgium, Canada, Germany, Denmark, Spain, Finland, France, the United Kingdom, Greece, Hungary, Italy, Japan, Netherlands, Portugal, Sweden, Turkey, and the United States. For the indicators measuring pollution abatement effort, poor data coverage causes our panel to be unbalanced.

${ }^{4}$ This transformation leaves the statistical and empirical analysis carried out in the following sections unchanged, but provides an easy visual way to compare the different indicators in Sections 3 and 4 and to interpret the associated coefficients in Section 5.
} 
Table 1: Descriptive Statistics for All Indicators, Country Averages 1995-2009

\begin{tabular}{|c|c|c|c|c|c|c|c|c|c|c|c|c|c|}
\hline & PACE_GDP & R\&D_GDP & ITRE & TET_GDP & EPS & MBEPS & NMBEPS & SUM6 & SUM15 & LATENT6 & LATENT15 & BL_CO2 & BL_PCA \\
\hline Australia & & 1.495 & & & 0.989 & 0.895 & 1.125 & 2.917 & 3.636 & 2.765 & 3.301 & 0.966 & 0.185 \\
\hline Austria & 7.992 & 0.953 & 1.631 & 4.720 & 4.959 & 5.386 & 4.444 & 8.056 & 6.768 & 6.404 & 6.661 & 6.249 & 3.831 \\
\hline Belgium & 4.107 & 1.355 & 0.338 & 4.481 & 1.972 & 0.729 & 2.931 & 3.611 & 4.394 & 3.542 & 4.642 & 2.912 & 1.534 \\
\hline Canada & & 2.200 & & & 3.286 & 3.986 & 2.667 & 5.139 & 5.303 & 4.274 & 4.042 & 1.518 & 0.566 \\
\hline Denmark & 4.090 & 1.474 & 8.045 & 8.958 & 5.601 & 4.719 & 6.056 & 7.639 & 7.222 & 7.534 & 7.143 & 2.391 & 2.706 \\
\hline Finland & 3.383 & 3.681 & 0.405 & 5.811 & 5.490 & 4.365 & 6.139 & 5.833 & 4.394 & 5.907 & 5.824 & 2.401 & 2.482 \\
\hline France & 4.156 & 2.429 & 2.560 & 3.968 & 2.986 & 3.267 & 2.708 & 5.417 & 6.667 & 5.948 & 6.572 & 6.346 & 2.289 \\
\hline Germany & 4.707 & 0.964 & 3.207 & 4.453 & 4.313 & 4.766 & 3.819 & 6.944 & 6.162 & 6.717 & 6.862 & 3.167 & 2.101 \\
\hline Greece & 1.181 & 0.467 & 1.174 & 4.568 & 2.531 & 3.178 & 2.000 & 5.938 & 5.795 & 5.701 & 6.037 & 2.192 & 3.472 \\
\hline Hungary & 4.675 & 4.381 & & 0.865 & 2.470 & 2.352 & 2.531 & 4.219 & 5.057 & 5.078 & 5.633 & 0.998 & 0.426 \\
\hline Italy & 6.167 & 1.429 & 6.186 & 5.580 & 2.425 & 2.563 & 2.292 & 5.972 & 7.273 & 5.334 & 6.195 & 3.939 & 2.503 \\
\hline Japan & & 4.347 & & & 3.184 & 4.246 & 2.292 & 4.583 & 5.707 & 4.497 & 5.611 & 5.695 & 7.565 \\
\hline Netherlands & 5.610 & 2.105 & 2.439 & 6.725 & 4.148 & 3.120 & 4.806 & 5.972 & 5.606 & 5.909 & 5.580 & 2.502 & 3.076 \\
\hline Portugal & 2.667 & 0.107 & 2.490 & 6.841 & 2.611 & 2.489 & 2.667 & 5.833 & 5.758 & 5.244 & 5.771 & 2.475 & 1.086 \\
\hline Spain & 3.242 & 0.641 & 1.900 & 3.410 & 3.773 & 5.227 & 2.542 & 6.806 & 7.929 & 6.287 & 6.574 & 3.510 & 1.924 \\
\hline Sweden & 2.074 & 1.568 & 2.986 & 5.469 & 4.260 & 4.197 & 4.167 & 5.000 & 4.697 & 6.179 & 6.299 & 7.953 & 4.027 \\
\hline Turkey & 1.007 & 0.129 & & & 0.624 & 0.554 & 0.765 & 2.206 & 2.032 & 1.062 & 1.575 & 1.932 & 1.560 \\
\hline United Kingdom & 2.509 & 0.411 & 3.324 & 4.766 & 2.202 & 1.510 & 2.722 & 3.889 & 4.949 & 4.435 & 5.377 & 3.562 & 1.813 \\
\hline USA & & 1.752 & & & 3.422 & 4.684 & 2.361 & 6.111 & 6.010 & 3.909 & 4.556 & 1.322 & 0.580 \\
\hline
\end{tabular}

Note: Indicator averages are not reported for those countries in which there are missing values. 
PACE, namely expenditures by the productive sectors on pollution abatement and control, is among the most popular early indicators of pollution abatement effort. This is notwithstanding the difficulties linked with the use of expenditure data highlighted in the previous section and the fact that the use of PACE data for countries other than the USA has historically proven difficult due to bad coverage statistics. ${ }^{5}$ Hence, the potential of PACE to serve as indicator of policy stringency is limited. Nevertheless it is important to include it in this analysis given the widespread use it has been subject to, and the fact that many of the early findings based on this indicator are still very relevant today (see, for instance, Jaffe and Palmer 1997). In our analysis, we use PACE as a percentage of GDP as retrieved from the EUROSTAT database to proxy for the environmental effort of a given country (EUROSTAT 2015). Scaling the PACE variable by GDP is necessary, especially when carrying out cross country comparison, to account for the size of a given country's economy, which would determine differences in the ability to sustain PACE expenditures by firms (PACE/GDP).

A second widely used proxy is data on government energy $R \& D$ expenditures. These inform on the willingness of each country to support and invest in carbon free technologies, and provide a clear signal and incentives for investors. Traditionally, energy R\&D investments have been among the most commonly used instruments to support the development of carbon-free and green technologies, with most countries introducing this form of support already in the early 1970s in the wake of the oil crisis (Hascic et al., 2010). While some differences exist in the statistics used to compute the country-level figures, the IEA Energy Technology R\&D Statistics Database (IEA 2015) provides information on Government R\&D expenditures to support a number of important energy technologies. ${ }^{6}$ As in the case of PACE statistics, we scale government R\&D expenditures in energy by the GDP of a given country to account for differences in the sizes of the economies considered (R\&D/GDP).

A third possible indicator of commitment to environmental policy is the implicit tax rate on energy (ITRE). While taxing energy goods and services may simply be a way to collect revenues on a good with a relatively inelastic demand, the effect of a higher implicit tax rate is that of reducing energy consumption. Since most energy until recently was produced using fossil fuels, a higher tax would have de facto the same impact of a stringent environmental policy regulation,

\footnotetext{
${ }^{5}$ For instance, comparable statistics are available only for the EU and do not allow the creation of a balanced panel dataset: see Rubashkina et al., 2015.

${ }^{6}$ The categories reported in the database include: fuel cells, fossil fuels power technologies, storage technologies, cross-cutting research, nuclear, energy efficiency, hydrogen, renewable energy and transport.
} 
resulting in lower energy consumption and associated emissions. Data on the implicit tax rate on energy is taken from EUROSTAT (2015).

The final candidate as proxy for environmental policy commitment is the amount of total revenue from environmental and energy taxes as a share of GDP (TET/GDP). Along the same lines of reasoning made above for the implicit tax rate on energy proxy, a higher revenue from environmental taxes relative to GDP would indicate a more stringent commitment towards environmental policy. Data on TET is taken from EUROSTAT (2015).

Figure 1: Proxies for Pollution Abatement Effort, 1995-2009

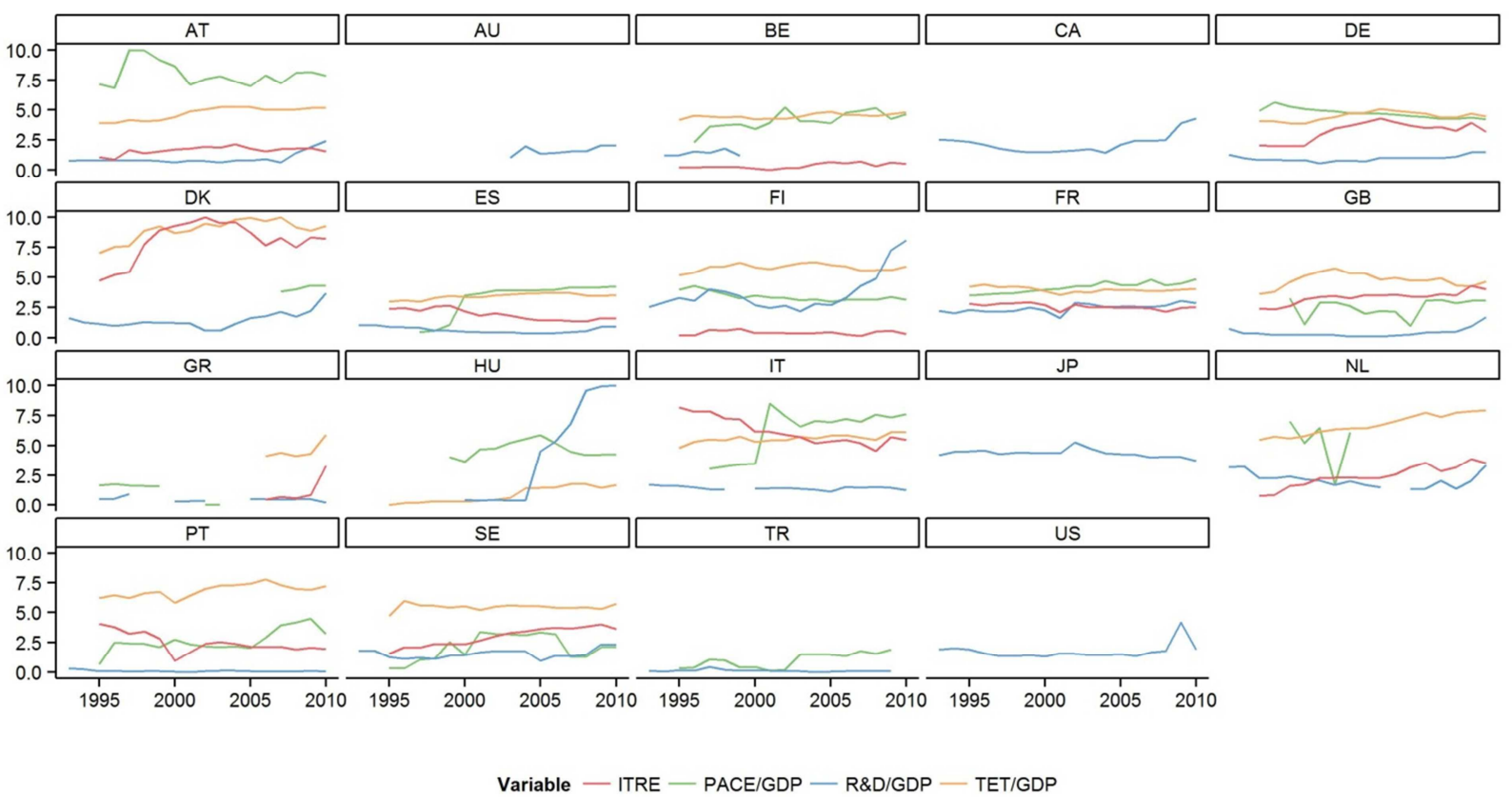

In Figure 1 we report the behavior across time and across countries of pollution abatement effort just described. From the figure it appears that, the indicators measuring private and public pollution abatement effort show significant heterogeneity across the countries in our sample, both in terms of level and in terms of time profile. Only in a few cases the indicators show that stringency/commitment of policy has increased over time (for instance, ITRE and TET/GDP in the Netherlands or RDD/GDP in Finland and Hungary). Only in the case of France the four indicators convey a very similar picture.

\subsection{Composite Indicators}


In order to build several composite indicators, we rely on a recent database produced by the OECD which was the basis for the creation of the OECD EPS composite indicator (Botta and Koźluk, 2014). The advantage of being able to building several indicators by relying on the same data source allows isolating changes in the indicators' performance that are entirely attributable to the aggregation technique, which is the scope of our comparative analysis. The data underlying the OECD EPS indicator provide a unique opportunity to do so, and have become available only recently.

The OECD database contains information on 15 different environmental policy instruments implemented in OECD countries, including both Non-Market Based (NMB) and Market Based (MB) instruments. NMB policies include limits to pollutants $\left(\mathrm{SO}_{\mathrm{x}}, \mathrm{NO}_{\mathrm{x}}\right.$, Particulate Matters and Sulphur Content of Diesel) and Government energy-related R\&D expenditures as a percentage of GDP. MB policies include feed in tariffs (FITs - solar and Wind), taxes (on $\mathrm{CO}_{2}, \mathrm{SO}_{\mathrm{x}}, \mathrm{NO}_{\mathrm{x}}$ and Diesel), certificates (White, Green and $\mathrm{CO}_{2}$ ) and the presence of deposit and refund schemes (DRS). All variables are continuous, except DRS which is a $0 / 1$ indicator for the presence of such schemes.

As said, the OECD database has been used to produce the OECD EPS composite indicator whose main features are the following. ${ }^{7}$ First, the 15 continuous policy indicators are categorized as a Likert scale from 0 to 6 by identifying specific bins. ${ }^{8}$ These 15 Likert-scale scores are then aggregated into 6 large macro-instruments: Taxes, Certificates, Limits, FIT, DRS and R\&D by using weights. Subsequently, these 6 indicators are aggregated into a MB score (Taxes, Certificates, FIT, DRS) and a NMB score (R\&D and Limits). Finally, the EPS Composite score is obtained as the average between the MB and NMB scores. Given its relevance for the present analysis, we compute the OECD EPS indicator and complement it with several other composite indicators proposed by the literature.

A second indicator we consider that has been increasingly used in empirical analyses on the inducement effect of environmental policy is build following Nesta et al. (2014). Specifically, a score of 1 is assigned to a country starting from the year in which it first implements a given policy instrument. The composite policy indicator is then computed by summing the different dummy indicators for each country and year. Given the information contained in the EPS database,

\footnotetext{
${ }^{7}$ We refer the interested reader to Botta and Koźluk (2014) for a detailed description of the methodology.

${ }^{8}$ Note, importantly, that these bins are not equally spaced. Rather, the authors derive them by analyzing the distribution of the underlying data. Also the weights used for aggregation (mentioned later in the section) are not equal. Hence, the process to build such indicator is rather time consuming and arguably involves judgement to a great degree.
} 
we build two such indicators: the first one, called SUM15, considers the 15 continuous variables for which we have information; the second one, called SUM6, only considers the 6 categorical aggregates listed above. ${ }^{9}$ The resulting two indicators inform on the diversification of the policy portfolio in a given country over time. ${ }^{10}$

A third type of composite indicator we compute is the one proposed in Galeotti et al. (2014). Indicators of this type are inspired by Item Response Theory (IRT) (De Boeck and Wilson, 2004). In an IRT model, the performance of each "subject" in the dimensions studied is the outcome of two different aspects: the "difficulty" of each of the items the subject is faced with and the "ability" of each subject, both of which are modelled as latent variables. In this basic dichotomous framework, which has been widely applied in the assessment of education attainments by students, the probability of observing a positive/correct response to each item by any given individual is a decreasing function of item difficulty/complexity and an increasing function of the subject latent trait, or "ability". ${ }^{11}$ The model can also accommodate scores on items that are measured on a Likert scale, as in the case at hand.

Building on the IRT framework, Galeotti et al. (2014) extend the application of the IRT model by proposing an ordinal logistic three-level random intercept (TLRI) model to assess the performance of countries with respect to environmental policy. ${ }^{12}$ The levels considered are "policy instrument $i$ "

\footnotetext{
${ }^{9}$ Vona and Nicolli (2012) also consider the average-based indicator which effectively amounts to the average of dummy variable indicators equal to zero before the instrument is put into place and equal to one afterwards.

${ }^{10}$ Another possible approach to a composite policy index could be built exploiting the continuous nature of the data available and would use Principal Component Analysis (PCA) on the OECD policy dataset (following, for example, Vona and Nicolli, 2012). This approach is statistically more sophisticated than that of the SUM6 and SUM15 indicators, as we discuss later in this section when we apply PCA to the emission-based data. The factor loadings resulting from the PCA can be interpreted as importance weights which vary by policy instrument. When we applied the PCA on the available data it proved very weak: the first component of the PCA only captured $25 \%$ of the variation within the sample. It is therefore not a good summary statistics for the variation of the underlying data. For this reason, we do not discuss this indicator in the paper. Evidence is available upon request.

${ }^{11} \mathrm{~A}$ standard application of IRT is in the realm of testing educational attainment in questionnaires, as difficulty of the various questions in the test and the ability of a student jointly determine the outcome of the test.

${ }^{12}$ The basic IRT model considers two levels: the item and the subject. Galeotti et al. (2014) set up a three level random intercept model to take into account a third dimension of their dataset, which is time. In the TLRI model, the first level is the item (in this specific case, the policy instrument under consideration), the second level is time and the third level is the subject (in this case, the countries). Galeotti et al. (2014) use this model to assess the performance of EU countries with respect to energy efficiency policies. Specifically, each country is assigned a score in each type of 5 policy instruments: regulatory policies, voluntary measures, financial instruments, fiscal/tax reductions, information/education. The score is equal to the number of laws/regulation which were active in each category at each point in time. Hence, in the specific application of Galeotti et al. (2014) the scores provided no information on the stringency of the policies, just on their presence. This differs from the approach used here, which assigns for each country a score which is higher, the higher the stringency of the policy.
} 
(level 1), "time $t$ " (level 2) and "country $c$ " (level 3) and allow to use the IRT model in a panel setting. ${ }^{13}$

In their framework, the probability of observing a given score $Y_{i t c}$ in country $c$ at time $t$ in policy instrument $i$ is given by the following: ${ }^{14}$

$$
P\left(Y_{i t c}=m \mid \theta_{0 t c}, \theta_{00 c}\right)=\frac{\exp \left\{\sum_{k=0}^{m}\left[\theta_{0 t c}+\theta_{00 c}-\left(\beta_{i}+\tau_{i k}\right)\right]\right\}}{1+\sum_{l=1}^{M-1} \exp \left\{\sum_{k=0}^{l}\left[\theta_{0 t c}+\theta_{00 c}-\left(\beta_{i}+\tau_{i k}\right)\right]\right\}}
$$

where $k$ is the threshold between two adjacent categories (scores) of a given item (policy), $(\beta+\tau)$ is the coefficient associated with each threshold, which can be interpreted as a measure of "difficulty". The third (country) level residuals $\theta_{00 c}$ indicate the average ability of country $c$, whereas the second (time) level residuals $\theta_{0 t j}$, inform on yearly changes from the third level residuals. Hence, the sum of the third and second level country residuals provides a time-varying country-level indicator which informs on the "ability" of a country $c$ to implement different policy instruments, which is conditional on the intrinsic difficulty of implementing each instrument estimated in the model (captured by $k$ and $(\beta+\tau)$ ). Recall that, as explained in Galeotti et al. (2014), this measure can be considered a proxy for each country's commitment to more stringent environmental policy.

To implement the TLRI model, we use the 15 Likert-scale scores produced by Botta and Koźluk (2014) in the OECD EPS indicator. A higher score in a given policy category indicates higher stringency of the policy. ${ }^{15}$ We estimate the TLRI model on the data, and compute country-level time varying indicators by summing the third and second level residuals for the model. This constitutes our indicator LATENT15. We repeat the same procedure using the data on the 6 categorical aggregates used in Botta and Koźluk (2014) to obtain the LATENT6 indicator.

Figure 2 and Figure 3 show the time profile of the composite indicators built using information on the 15 and the 6 policy instruments, respectively and the OECD EPS composite indicator. Appendix A contains additional graphs showing the evolution of the OECD MBEPS and NMBEPS indicators as well as of the SUM6 and SUM15 indicators.

\footnotetext{
${ }^{13}$ The traditional two level model would include only the levels "policy instrument" (level 1) and country (level 2), and would be applicable to a cross section.

${ }^{14}$ Galeotti et al. (2014) also complement this with a latent regression which allows cleaning the estimated latent trait from the effect of observables likely to affect both policy instrument choice and implementation. This gives rise to a second country ranking based on the third level (country) residual from the explanatory model that accounts for the role of covariates.

${ }^{15}$ Given that the econometric model we present here requires that each adjacent category is non-empty, in a few cases where scores in the middle of the distribution were not assigned to any country (hence represented an empty cell) we simply eliminate the cell and rescale all higher values by subtracting 1 .
} 
Figure 2: Composite Indexes: EPS, SUM15 and LATENT15, 1995-2009

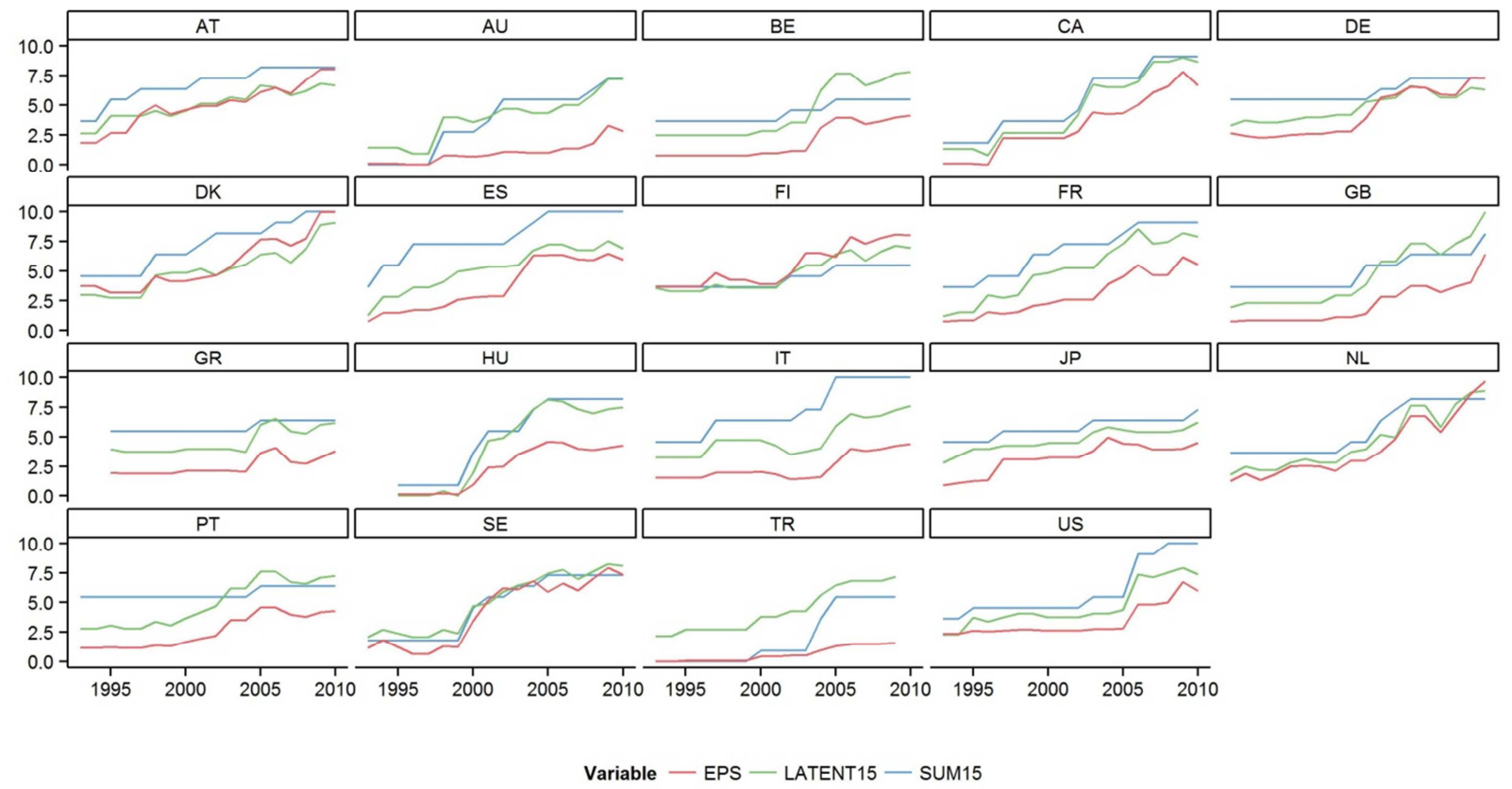

Figure 3: Composite Indexes: EPS, SUM6 and LATENT6, 1995-2009

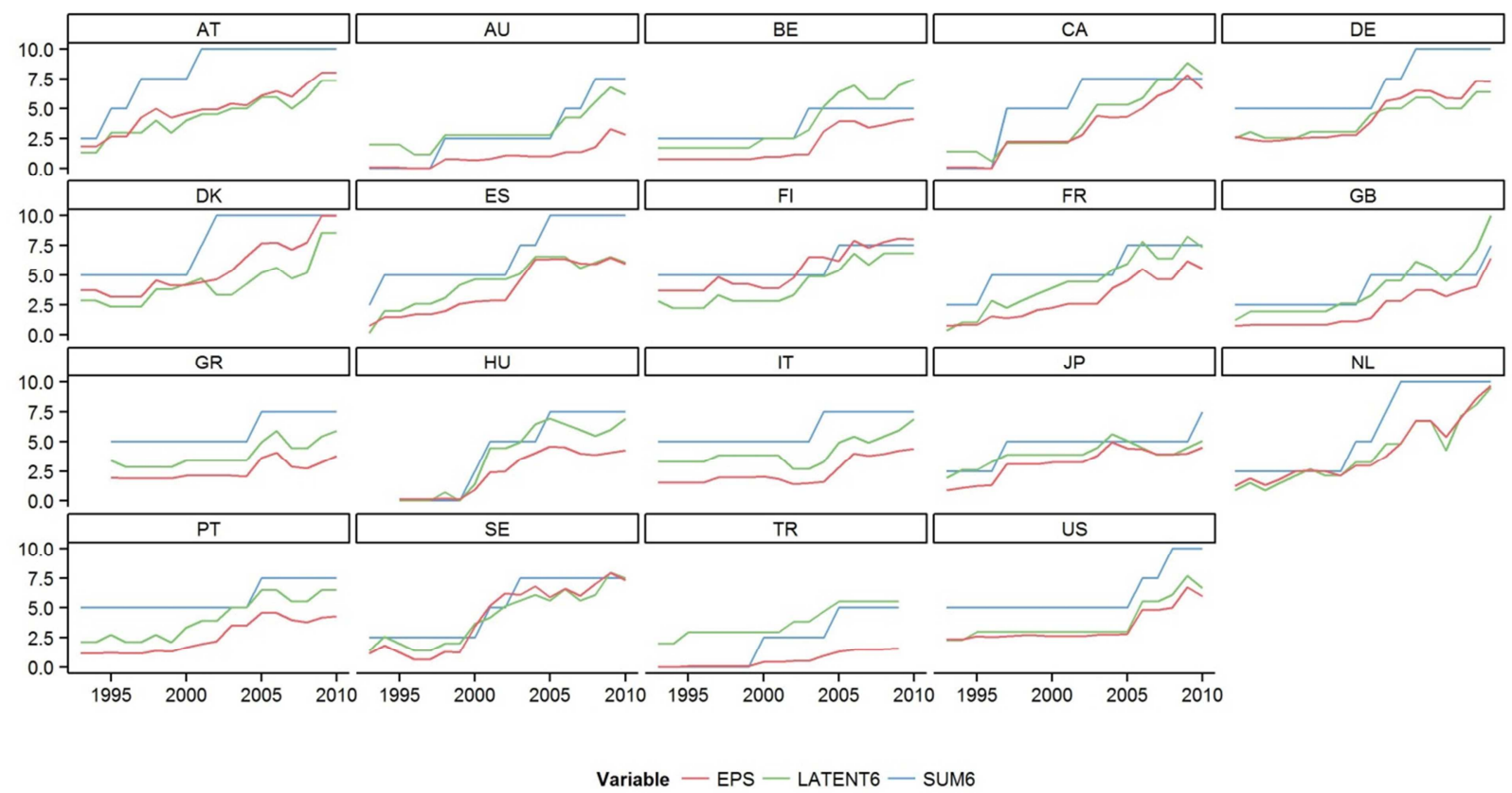

Note that in this case, unlike the case of the proxies for pollution abatement effort, the indicators convey very similar information, both with respect to level and time profile. As expected, the variability of the SUM15 and SUM6 indicators is much lower than that of the other two proxies. Furthermore, the LATENT and the EPS scores are very similar. For instance, the case of 
Netherlands, Sweden and Denmark and Austria they basically overlap, while for other countries they show a similar time profile, but different levels.

\subsection{Emission-based Indicators}

The emission-based proxies we propose in this paper are computed using data from the World Input-Output Database (WIOD, 2014).

The first indicator is based on the methodology proposed by Brunel and Levinson (2013) and is calculated as the ratio $R_{j}$ of predicted or "counterfactual" emission intensity to actual emissions intensity of a given country as follows:

$$
R_{j}=\frac{\hat{e}_{j}}{e_{j}}=\frac{\sum_{i} \frac{V_{i j}}{V_{j}} e_{i}}{\frac{E_{j}}{V_{j}}}=\frac{\sum_{i} \frac{V_{i j} E_{i}}{V_{j} V_{i}}}{\frac{E_{j}}{V_{j}}}
$$

where $i$ indicates the sector and $j$ indicates the country, $e$ indicates emission intensity, $E$ emissions and $V$ value added. Actual (observed) emission intensity is defined as emissions per value added in a given country. The "counterfactual emission intensity" $\left(\hat{e}_{i}\right)$ is a prediction of expected emissions from that country based on its industrial composition $\left(V_{i j}\right)$ and the average emission intensity of each sector in all countries $\left(e_{i}\right)$. Countries that impose more stringent regulation will have lower-than-predicted emission, hence higher levels of $R_{j}$.

We adopt the Brunel and Levinson (2013) approach as it is more sophisticated than using the actual values of emission intensity per each country and year. As they highlight, such indicator comes a long way toward overcoming some of the shortcomings of previously proposed emissionbased measures; specifically, is it theoretically motivated by pollution abatement costs, it is timevarying by country, and it accounts for a country's sectoral composition.

We compute a Brunel and Levinson indicator following equation (2) using information on carbon dioxide emissions in Kilotons aggregated across 26 energy carriers and data on value added by sector expressed in monetary units in 1995 prices and then converted to million US dollars using market exchange rates (BL_CO2).

In addition to including information on $\mathrm{CO}_{2}$ emissions, WIOD also collects data on other pollutants: sulfur oxide $\left(\mathrm{SO}_{\mathrm{x}}\right)$, Nitrogen oxide $\left(\mathrm{NO}_{\mathrm{x}}\right)$, non-methane volatile organic compounds (NMVOC), ammonia $\left(\mathrm{NH}_{3}\right)$, nitrous oxide $\left(\mathrm{N}_{2} \mathrm{O}\right)$, carbon monoxide $(\mathrm{CO})$, methane $\left(\mathrm{CH}_{4}\right)$. We compute a BL indicator following equation (2) for each of these pollutants. Detailed descriptive statistics of these indicators are provided in Appendix B. 
Given the high number of pollutants (and hence indicators), we applied a Principal Component Analysis (PCA) approach of the various emission-based indicators to explore whether they could be successfully summarized by a synthetic statistics. PCA allows reducing a number of (possibly) correlated variables (representing as many characteristics of the analyzed phenomenon) to a (smaller) number of latent variables called principal components. The first principal component accounts for as much of the variability in the data as possible and each subsequent component accounts for as much of the remaining variability as possible. Such an approach has been proposed, for example, in Vona and Nicolli (2012) to summarize the presence of several policy instruments at the country level. Details on our PCA are reported in Appendix B: the analysis indicates that the first components accounts for most of the variability in the data (almost 51 percent) and is positively correlated with all the underlying indicators. ${ }^{16}$ Hence, the first component can be reasonably used as a summary measure for all emission-related indicators.

We now turn to the comparison of the indicators presented above. We are interested in understanding to what extent the information they convey is similar. There are two important aspects of this question that need to be addressed: differences between countries and differences within countries. We explore the first issue in the following Section through a statistical analysis of the average country rankings which emerge in the sample. Insights emerging from this comparison are relevant both to summarize the performance of countries over specific periods of times, and when considering cross-sectional differences and analysis. The second issue, namely differences in the ability to capture within-country variations, namely variations in a panel setting, is explored in Section 5.

\section{Comparison of Environmental Policy Stringency Indicators: Country Rankings}

In this section, we explore whether the various indicators presented above convey similar information with a focus on between country variations. This is an important issue for two reasons.

Figure 4 shows the time profiles for the BL_CO2 and the BL_PCA indicators, which generally behave quite similarly, both in terms of absolute values and time profiles.

\footnotetext{
${ }^{16}$ This is unlike the case of the 15 continuous indicators included in the OECD EPS database discussed in Section 3.
} 
Figure 4: Emission-based Indicators

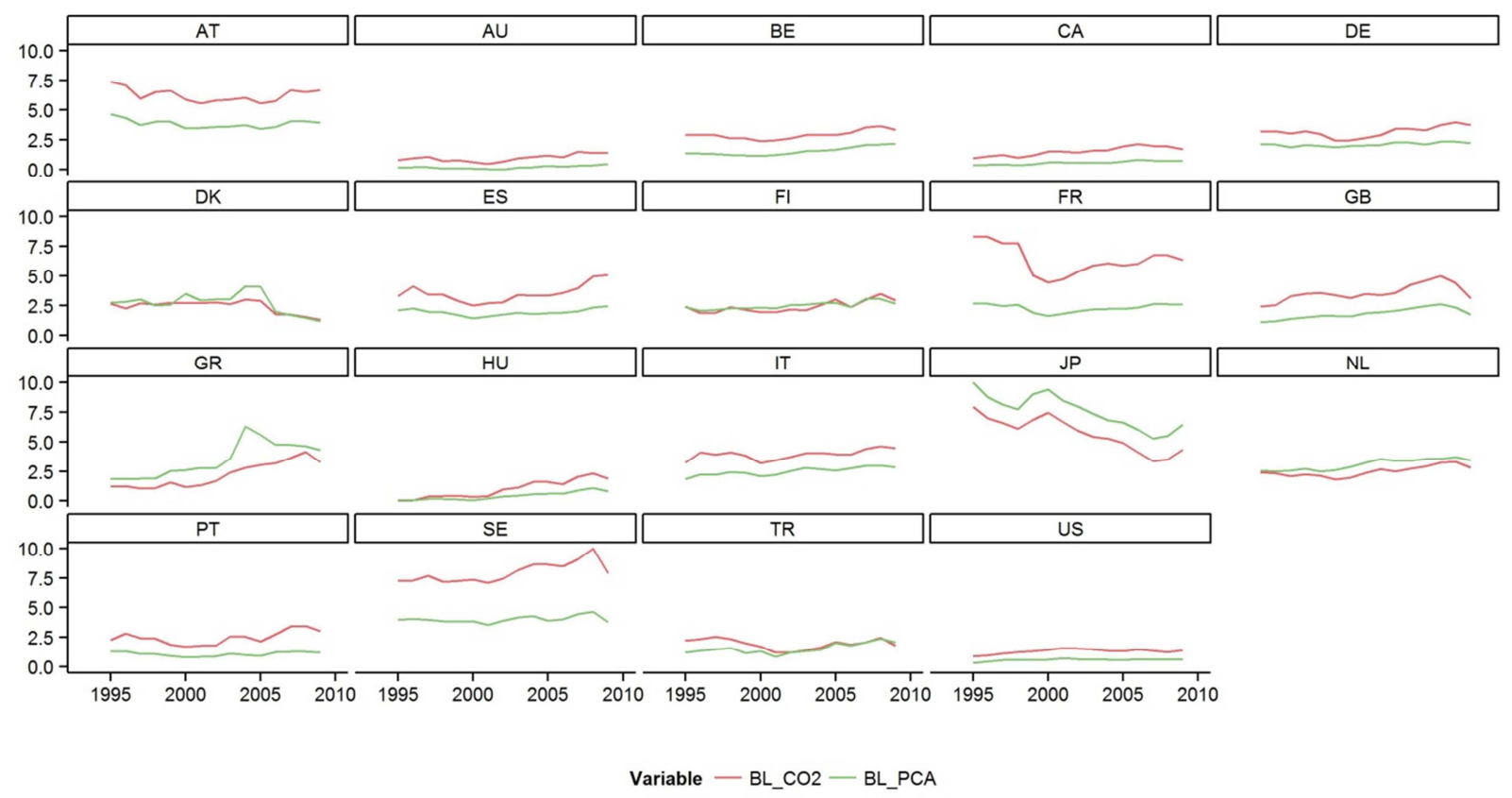

First, there is the interest in ranking countries with respect to their ability to implement environmental policies. This is, for instance, the aim of the OECD policy indicator as presented on the OECD website, where nice figures are shown that rank all OECD countries from the worse to the best performer. Clearly, if different indicators give rise to similar rankings, then such rankings are rather robust. Conversely, if the rankings are sensitive to the choice of indicator then no robust conclusions can be drawn in this respect. Second, the agreement or disagreement of country rankings for different indicators has significant implications for any cross-section empirical analysis, which exploits between country variations to identify the relevant coefficient.

The rankings we present here are built using information on the average value of the specific indicator for each country over the sample period. ${ }^{17}$ The Spearman correlation, reported in Table 2, shows that the indicators are generally positively correlated with each other. There is only one case of negative correlation, between ITRE and BL_CO2. As evidenced from Figure 1, the correlation among the pollution abatement efforts indicators is rather low, while it is higher among the composite indicators and between the BL_CO2 and the BL_PCA indicators. Overall, the indicators that display higher average correlations are LATENT6 and LATENT15.

\footnotetext{
${ }^{17}$ We concentrate here on the main indicators, which we presented in the previous section. For the indicators included in the appendix, results are available from the authors.
} 
Table 2: Spearman Correlation Matrix Among Alternative Indicators

\begin{tabular}{|c|c|c|c|c|c|c|c|c|c|c|c|c|c|}
\hline & PACE/GDP & R\&D/GDP & ITRE & TET/GDP & EPS & MBEPS & NMBEPS & SUM6 & SUM15 & LATENT6 & LATENT15 & BL_CO2 & BL_PCA \\
\hline PACE/GDP & 1 & & & & & & & & & & & & \\
\hline R\&D/GDP & 0.14 & 1 & & & & & & & & & & & \\
\hline ITRE & 0.02 & -0.14 & 1 & & & & & & & & & & \\
\hline TET/GDP & -0.10 & -0.15 & 0.59 & 1 & & & & & & & & & \\
\hline EPS & 0.35 & 0.28 & 0.14 & 0.37 & 1 & & & & & & & & \\
\hline MBEPS & 0.33 & 0.19 & 0.16 & 0.21 & 0.88 & 1 & & & & & & & \\
\hline NMBEPS & 0.30 & 0.31 & 0.09 & 0.44 & 0.92 & 0.63 & 1 & & & & & & \\
\hline SUM6 & 0.48 & 0.11 & 0.24 & 0.34 & 0.85 & 0.85 & 0.70 & 1 & & & & & \\
\hline SUM15 & 0.47 & 0.15 & 0.37 & 0.19 & 0.73 & 0.73 & 0.61 & 0.87 & 1 & & & & \\
\hline LATENT6 & 0.41 & 0.19 & 0.33 & 0.34 & 0.85 & 0.75 & 0.79 & 0.81 & 0.78 & 1 & & & \\
\hline LATENT15 & 0.42 & 0.21 & 0.28 & 0.22 & 0.83 & 0.75 & 0.76 & 0.83 & 0.87 & 0.95 & 1 & & \\
\hline BL_CO2 & 0.21 & 0.13 & -0.05 & 0.03 & 0.28 & 0.30 & 0.21 & 0.25 & 0.25 & 0.38 & 0.41 & 1 & \\
\hline BL_PCA & 0.29 & 0.32 & 0.07 & 0.39 & 0.27 & 0.28 & 0.20 & 0.21 & 0.18 & 0.30 & 0.32 & 0.69 & 1 \\
\hline
\end{tabular}

Based on the average value over the sample period for each indicator we produce country rankings, which are displayed in Table 3 and in Figure 5, which confirms once again that the different indicators are not in agreement. In table 3, lighter colors indicate less stringency, while darker colors indicate more stringency. In Figure 5, the bigger the slice of the pie, the higher the ranking of the given country for the given indicator.

\section{Table 3: Rankings Associated with Alternative Indicators}

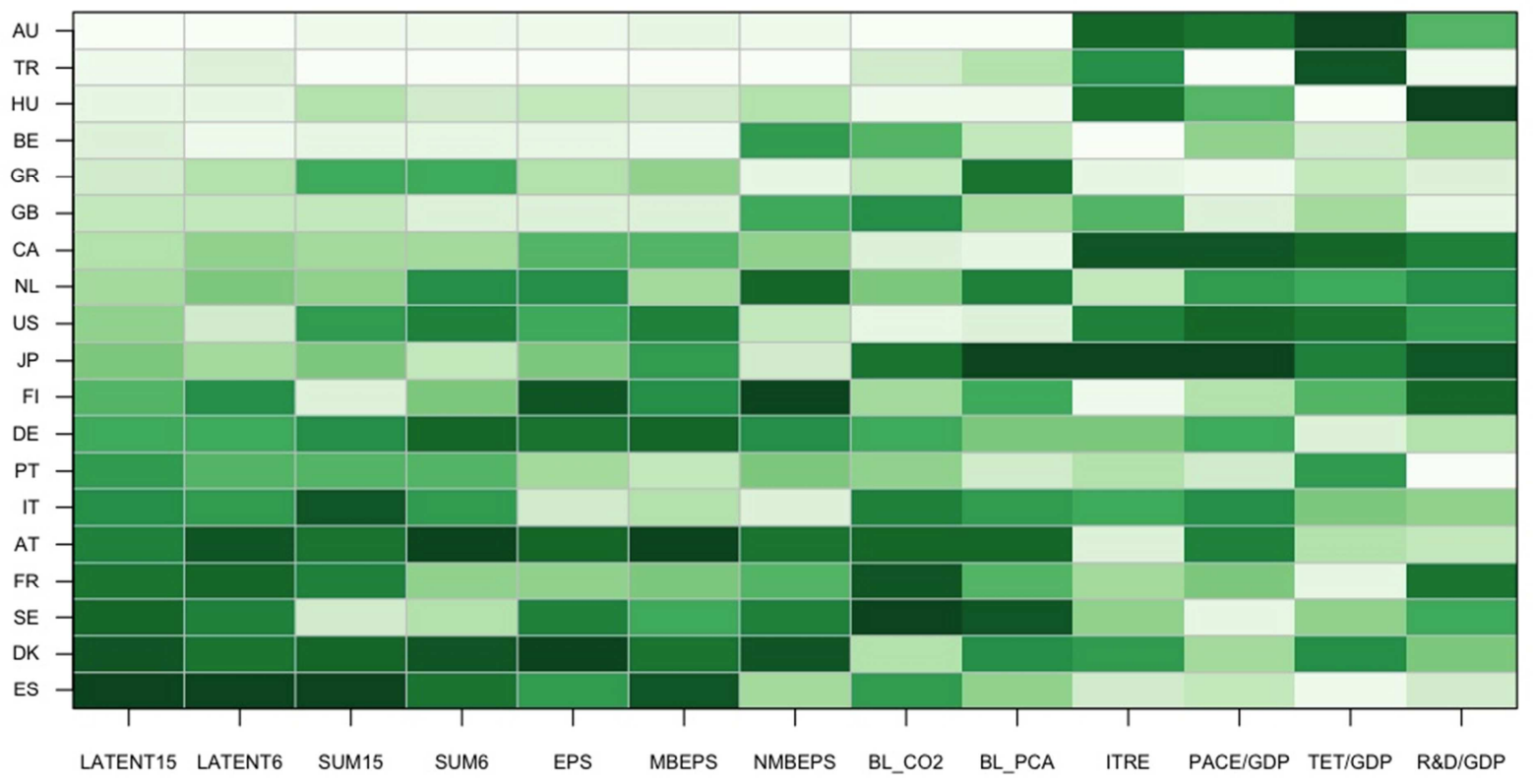


Figure 5: Rankings of Policy Indicators, by Country

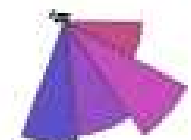

$\mathrm{AU}$

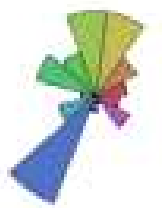

GR

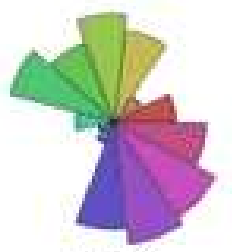

US

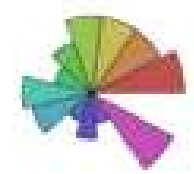

PT

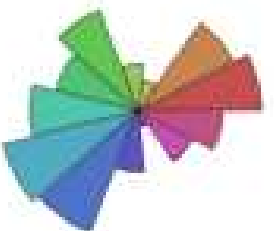

SE

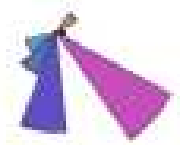

TR

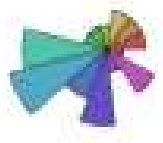

GB
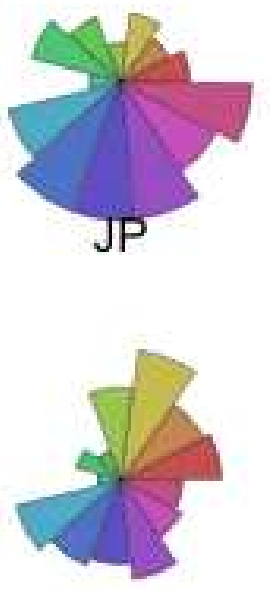

IT

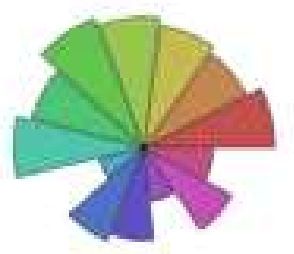

DK

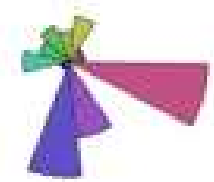

$\mathrm{HU}$
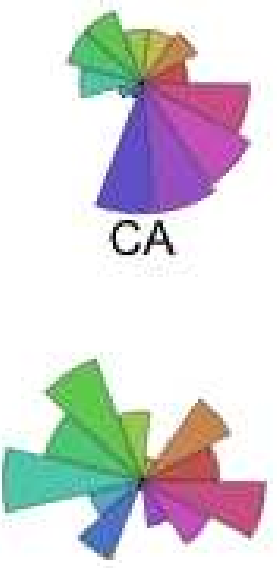

$\mathrm{FI}$

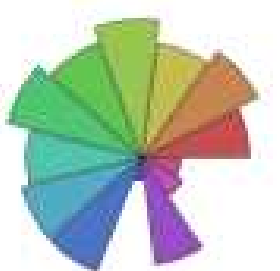

AT

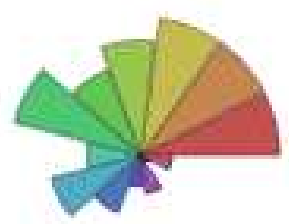

ES

BE
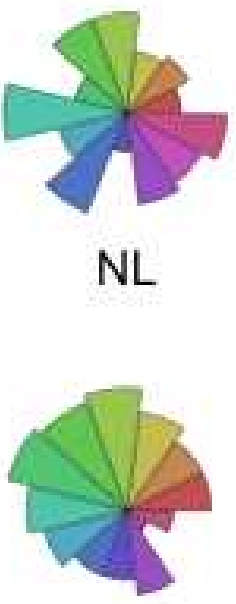

DE

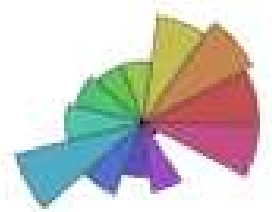

FR

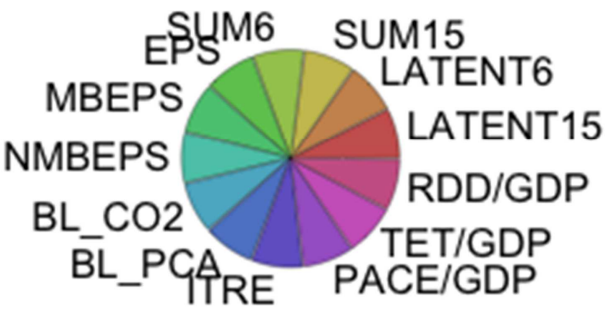


Generally speaking, the agreement is higher between the composite and emission-based indicators, while the indicators based on pollution abatement give rise to significantly different country rankings. In some cases (for instance Belgium, Denmark and Germany), the position of countries within sample is generally stable across indicators. In other cases (for instance, Canada and Greece), using different indicators can give rise to completely different insights. Differences between ex-post and ex-ante indicators may reasonably hide differences in the effectiveness of policy implementation and monitoring, or the fact that some indicators do not take into account the "intensity" of the implemented policies (this is the case for the SUM6 and SUM15 indicators, which have often been used in the literature). Furthermore, in the case of the SUM6 and SUM15 indicators, it can be argued that it is indeed the countries with lowest performance (i.e. low ranking in emission-based or pollution effort indicators) that need to implement a more complex portfolio of policy instruments to address pressing environmental issues. If a country is already doing well, further regulation may not be needed. This reasoning does not however apply to the EPS and other composite indicators, which take into account the stringency of the implemented policy.

To further characterize the distance between these metrics, Figure 6 presents a dendogram, a tree diagram frequently used to illustrate the arrangement of the clusters produced by hierarchical clustering. In the dendrogram, each indicator is positioned according to its distance with the other indicators. Indicators with higher similarity cluster into nodes. The height indicates how far away the indicators within the different clusters are. Specifically, the height of each node in the plot is proportional to the value of the intergroup dissimilarity between its two whiskers.

Consistent with what presented above, the dendogram shows that the several composite indexes we compute are closer to each other than they are to emission-based indicators or to the indicators measuring pollution abatement effort. Interestingly, PACE/GDP and R\&D/GDP are rather close to each other, indicating that in general public and private measures of pollution abatement effort provide consistent country rankings. SUM6 and SUM15 indicators are very similar, as are the BL_CO2 and the BL_PCA metrics and the EPS and MBEPS ones. In Appendix C we provide a similar dendogram that clusters the different countries based on the information contained in all the indicators.

The statistical analysis presented to so far has shown that the country rankings are not robust to the choice of indicator. This is particularly troublesome if such indicators where to be applied in cross section analysis of between country differences, as they would will give rise to different 


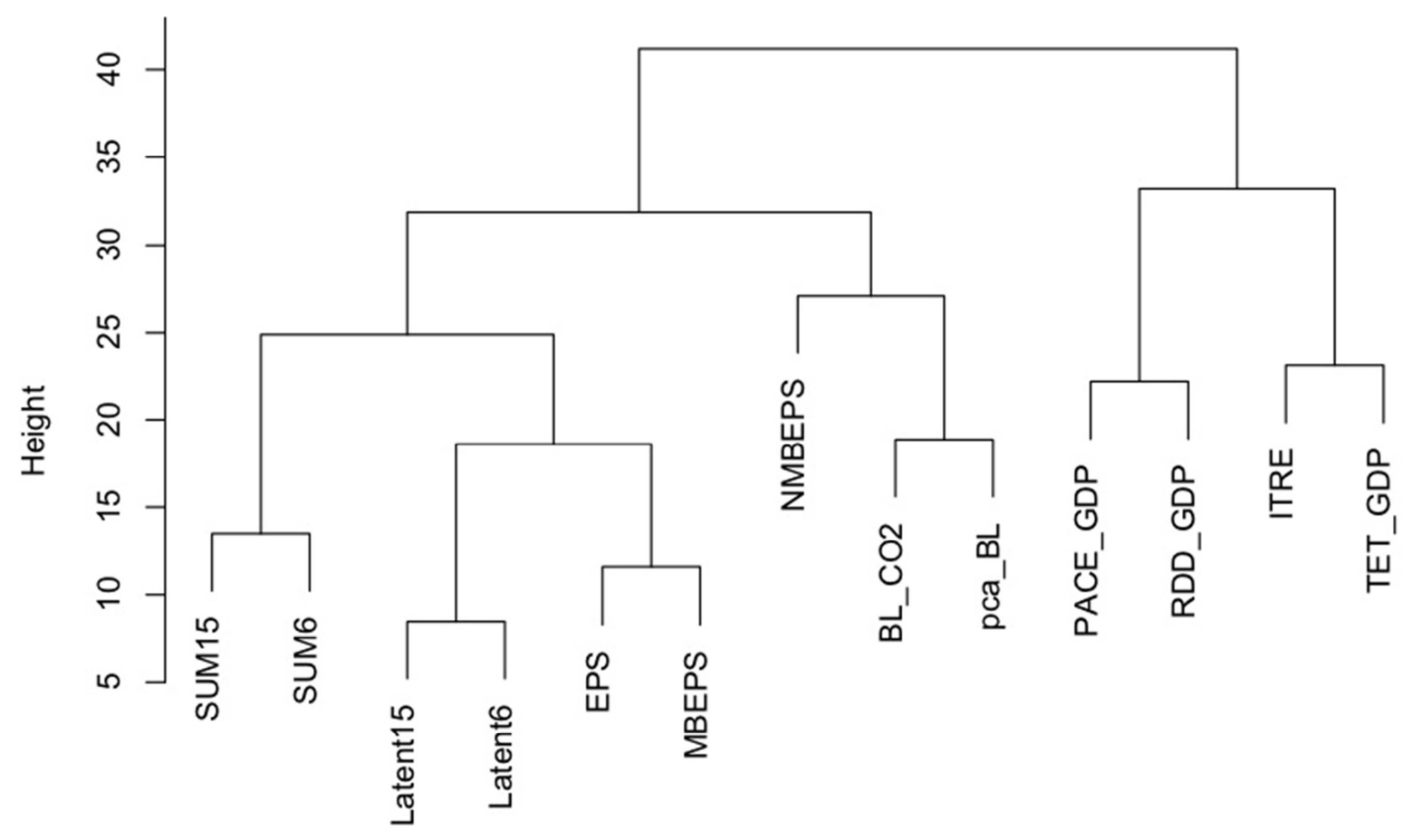

results. In the next section, we explore whether this holds true when analyzing within-country variations in a panel setting through an empirical application.

\section{Comparison of Environmental Policy Stringency Indicators: Within-country Variation and Empirical Application to Energy Efficiency}

An additional dimension of the comparison of alternative indicators of environmental policy stringency is whether they capture similar or different dynamics of within-country variations. This issue is best studies through an empirical application which will highlight how the different indicators perform in practice.

While economists are typically concerned with the efficiency properties of environmental policy instruments, what ultimately matters is whether or not those policies are effective in reaching the proposed targets and goals. Loosely speaking, goals are stated in terms of environmental targets emissions or pollution reduction - or in terms of economic performance and competitiveness. As mentioned in the Introduction, the empirical evidence with respect to the impact of environmental policy on macroeconomic variables or firm performance and consumer behavior presents conflicting results. One is thus left to wonder whether such differences are indeed real, which 
would mean that environmental policy has somewhat of an idiosyncratic effect, or whether they depend more on empirical design and specifically on the choice of proxy for policy stringency.

In this section we try to shed light on this issue by studying the possible differential implications of using one or the other indicator for fostering a country's energy efficiency/energy productivity. Specifically, we test whether countries with more stringent environmental and energy policy have indeed increased the efficiency in the use of their energy inputs more than countries with lax policy. Increased energy efficiency encompasses improvements in existing energy technologies, introduction and diffusion of new technologies, more modern and advanced infrastructure networks, more rational use of energy. Environmental regulation, primarily motivated by energyrelated emission control, is in principle able to foster technological innovation, to provide stimuli for consumers to efficiently use energy, to generate incentives for investment in better and more efficient infrastructures. The efficiency of energy use should therefore be enhanced by effective environmental policies.

Of course, the above mentioned improvements are possible only in a context of economic growth. Indeed, growth implies an increased demand for environmental protection, while making it possible to allocate the financial resources necessary for implementing those changes in energy systems. Thus, economic growth entails per se an increase in total energy use, as increased production volumes require more energy, but also allows for a more rational use that may even result in a lower energy intensity of the economy. This is presumably where environmental policies play a role.

We investigate this issue within a Kuznets Curve framework. The Environmental Kuznets Curve (EKC) literature (Lieb, 2003, for a survey among many others) has been mostly focused on carbon dioxide emissions (for instance, Galeotti, Lanza, and Pauli, 2006), the largest greenhouse gas responsible for climate change. The main argument in this literature is that the relationship between carbon dioxide emissions and GDPis characterized by an inverted U-shape. As a country grows, it will increase $\mathrm{CO}_{2}$ emissions up to the point where it becomes wealthy enough to start to worry about quality of life and of the environment. From that point onward, carbon emissions of the economy decline.

Because around $70 \%$ of $\mathrm{CO}_{2}$ emissions are generated by the combustion of fossil fuels, and because coal, oil and gas are the major sources of energy currently in use worldwide, some economists have looked directly at energy consumption to study the existence of a Kuznets-like behavior (Suri and Chapman, 1998; Judson, Schmalensee, and Stoker, 1998; Agras and Chapman, 
1999). Moreover, in resource-poor countries energy dependence from abroad may provide a powerful stimulus to economize on energy. More generally, and independently of environmental considerations, conserving energy contributes to lessening the pressure on exhaustible resource depletion. $^{18}$

The "Energy Kuznets Curve" may display an inverted-U behavior for the same reasons as carbon dioxide. In particular, we are interested in finding out if there are indications in the data that may suggest that per capita energy consumption is increasing with income but at a slower pace or is even declining as per capita income rises further. This behavior, if present, would suggest that energy intensity is declining and the contribution of energy to GDP - Energy Productivity - is on the rise. Conditional on that, we are then interested in assessing whether a more stringent environmental policy fosters brings about a reduction in energy intensity. That would imply that the shape of the energy intensity-to-GDP relationship would shift downward as a result of effective energy and environmental policies. Indeed, the estimate size of this effect could depend on the specific proxy chosen for environmental policy stringency.

In keeping with the EKC literature, per capita energy use is taken to depend upon per capita income:

$$
E / P=g(Y / P)
$$

where $E$ is total energy use, $Y$ is GDP and $P$ is total population. The Kuznets curve literature has been typically interested in the curvature of the environment-income relationship, in particular its possible inverted-U shape, and in the location of the income turning point where the curve starts declining. The decoupling is evidenced by the negative sign of the second derivative of $g(.){ }^{19}$ The most convenient parametrization of the energy-income relationship is a log-linear polynomial function of income:

$$
\ln \left(\frac{E}{P}\right)_{i t}=\alpha_{0}+\alpha_{i}+\gamma_{t}+\alpha_{1} \ln \left(\frac{Y}{P}\right)_{i t}+\alpha_{2}\left[\ln \left(\frac{Y}{P}\right)\right]_{i t}^{2}+\alpha_{3} I_{i t}+\varepsilon_{i t}
$$

where we have added variable $I$ to represent our alternative indicators of environmental policy stringency and where country-specific $\alpha_{i}$ and time-specific effects $\gamma_{t}$ have been allowed for,

\footnotetext{
${ }^{18} \mathrm{~A}$ further reason for taking energy is its nature of wide encompassing indicator of human pressure on nature, whereas pollution has to either rely on many indicators or on composite, arbitrarily weighted scalars.

${ }^{19}$ This is not enough for a Kuznets curve, though. A negative second derivative is only necessary for "absolute" decoupling. Indeed, we need to consider also the first derivative of $g($.$) . If the first derivative is also negative, as in the$ declining portion of the EKC to the right of the turning point, then we have absolute decoupling. In addition, if the second derivative of the function is negative over some range of value of $y$ and then turns positive over the subsequent range, then a $\mathrm{N}$-shaped relationship would occur. When the second derivative is positive, then we speak of relinking.
} 
together with the disturbance term $\varepsilon_{i t}$. Note that the standard Kuznets relationship (4) is expressed in per capita terms. However, in keeping with the concept of energy efficiency, we can exploit the logarithmic properties of (4) and reformulate it as follows:

$$
\ln \left(\frac{E}{Y}\right)_{i t}=\alpha_{0}+\alpha_{i}+\gamma_{t}+\left(\alpha_{1}-1\right) \ln \left(\frac{Y}{P}\right)_{i t}+\alpha_{2}\left[\ln \left(\frac{Y}{P}\right)\right]_{i t}^{2}+\alpha_{3} I_{i t}+\varepsilon_{i t} \text { where energy }
$$

intensity, instead of energy consumption per capita, is the dependent variable. The only difference is the coefficient of the linear per capita GDP term.

We estimate equivalently (4) or (5) assuming that country and time effects are fixed, and thus possibly correlated with the error term. Data on Total Primary Energy Supply (TPES) and on Total Final Energy Consumption (TFEC) - measured in Mtoe - are taken from IEA World Energy Statistics and Balances (various years). Population (POP) and GDP in US dollars in 2005 PPP prices data are from the National Accounts of OECD Countries. ${ }^{20}$ We use these data together with the environmental policy indicators described above on our sample which covers the period 19952009 for the 19 countries under examination. A within estimator econometric method is used.

The results are presented in Tables 4 and 5. In each table we present the evidence for $E$ being proxied by both TPES and TFEC; the tables differ because the policy indicator is entered either current or lagged, on the account of issues of potential endogeneity of the regressor. In the first column we report the results without any policy variable, whereas the remaining columns are associated with the main indicators discussed before. We first consider the pollution abatement indicators (PACE/GDP, RDD/GDP, TET/GDP, ITRE), followed by the composite indicators (SUM6, SUM15, EPS, MBEPS, NMBEPS, LATENT6, LATENT15) and finally the emissionbased Brunel and Levinson indicators. ${ }^{21}$

If we first focus on the relationship between energy intensity and income, we see that all GDP coefficients are highly significant and the signs are as expected. Indeed, the implied graphical representation shows inverted-U Kuznets curves characterizing all cases analyzed.

Focusing on environmental policy indicators and looking first at their statistical significance, a clear pattern can be seen. Indicators capturing pollution abatement efforts are generally

\footnotetext{
${ }^{20}$ We measure energy intensity as the ratio of either TPES or TFEC. Between these two energy variables is the energy transformation sector, largely given power generation and refinery of oil products. A reduction in energy intensity as a result of energy efficiency improvements - could be measured both from the perspective of final consumers (the "outputs" of energy transformation activities) and from the perspective of energy producers (the "inputs" of energy transformation).

${ }^{21}$ In Tables D.1 and D.2 of Appendix D we present the results of the estimation of equation (4) where the dependent variable is energy per capita. It is immediate to see, as noted in the text, that all estimated coefficients and associated $\mathrm{t}$-statistics are the same as those of Tables 4 and 5 with the exception of the $\ln (\mathrm{Y} / \mathrm{P})$ regressor.
} 
insignificant, with the notable exception of the implicit tax rate of energy (ITRE). The set of composite indicators is, on the contrary, almost always statistically significant, with the notable exception of the market-based OECD policy indicator (MBEPS). Finally, of the two BrunelLevinson indicators considered, only the $\mathrm{CO}_{2}$ emissions-based indicator is significant, whereas the indicator based on the PCA of various pollutants is never significant. ${ }^{22}$ Turning to the sign of the coefficients, in nearly all cases they are negative, The negative and statistically significant impact of most indicators impact implies that several of the analyzed proxies suggest that the overall shape of the energy intensity - income relationship shifts downward as a consequence of environmental policies, thus bringing about an improvement in the economy's productivity of energy. When the parameters are statistically significant, the only notable case of a positive sign is that of total revenue from environmental and energy taxes as a share of GDP (TET_GDP) (the other case of a positive sign is BL_PCA, which is however never significant ${ }^{23}$ ). Generally speaking, no relevant differences emerge when considering TPES or TFEC as proxies of energy consumption. The OECD EPS indicator is not significant in the TFEC case, whereas the coefficients of policy indicators are generally slightly larger in the TPES case.

The empirical application presented here gives rise to two important insights. First, the choice of indicator matters: proxies for pollution abatement efforts would suggest that environmental policy does not impact the energy intensity of a given economy, and would lead to the conclusion that environmental effort is in fact not effective. On the contrary, the use of composite and emissionbased indicators would suggest that indeed environmental policy and its stringency do contribute to lowering the energy intensity of an economy, and to a more efficient use of energy.

Second, the size of the coefficients is generally similar with the notable exception of ITRE, which is about twice as large as that of SUM15, LATENT15 and BL_CO2 and about four times larger than that of the other coefficients. Given that our indicators are normalized, the specification we present here suggests that a 10 percent increase in any of the significant composite or emissionbased indexes (which is equivalent in our case to a 1 unit increase) would result in a decrease in energy intensity in the range of 0.5 to 1 percent. This is arguably a weak impact of environmental policy on energy intensity. However, it is important to remember that the period under

\footnotetext{
${ }^{22}$ This evidence is confirmed by the empirical analysis we conducted for each individual pollutant of the WIOD database. A Brunel and Levinson indicator was constructed in each case and the various version of our econometric model estimated. The results are presented in the appendix D, Tables D.3 and D.4. It can be seen that the only statistically significant cases involve $\mathrm{NO}_{\mathrm{X}}$ and $\mathrm{N}_{2} \mathrm{O}$ but the sign of the coefficients is positive.

${ }^{23}$ The lack of significance of the BL_PCA indicator is hardly surprising given the results of the PCA analysis form which it is built. In particular, the BL_PCA indicator represents the first Principal Component, which in the case at hand captures only half of the variation across the different indicators. See Appendix B.
} 
consideration saw the beginning of environmental policy commitment by the countries in our sample, with policies that were not particularly stringent or ambitious and characterized by rather slow implementation. One can only assume that, as later data will become available, such picture may be partly revised.

We conclude by portraying the energy Kuznets curves implied by the case of no environmental policy indicator and the one where LATENT15 is included, based on the estimated coefficients of Table 4, upper panel. It can be seen that the environmental policy stringency index shifts the inverted-U curve downward and makes the curve less "pointy" moving slightly rightward the income turning point. $^{24}$

\section{Conclusions}

This paper has presented several indicators of environmental policy stringency proposed in the literature, which include indicators measuring pollution abatement effort by both the public and the private sectors, composite indicators and emission-based indicators. A comparative analysis was conducted of how such indicators capture between-country variations by focusing on the difference in average rankings over the sample period. It also shed some light on whether they differ in capturing within-country variation through an empirical application focuses on energy efficiency.

Results show that the country rankings are not robust to the choice of indicators. Hence, rather than relying on a single indicator, the literature should work towards considering several indicators and possibly constructing a synthetic measure.

The performance of the various indicators in the empirical analysis is in line with the results emerging from the study of country rankings: composite and emission-based indicators tend to provide a similar picture, while proxies based on pollution abatement effort a very different one.

\footnotetext{
${ }^{24}$ Given the panel specification of the model, the slope coefficients, i.e. the coefficients of the per capita GDP terms, and of the policy indicators are common to all countries but there are as many intercepts as there are countries and years. First, we took the average value of the estimated coefficients corresponding to each time dummy and to each year. Next, we substituted these values and the estimated income coefficients in the right hand side of (5), let per capita income increase progressively from $\ln (1)$ to $\ln (70)$ with 0.2 steps, set the residuals equal to zero and plotted the resulting curves.
} 
Table 4: Energy Efficiency Kuznets Relationship - Current Policy Indicators

\begin{tabular}{|c|c|c|c|c|c|c|c|c|c|c|c|c|c|c|}
\hline & \multicolumn{14}{|c|}{ TPES/GDP } \\
\hline & & PACE/GDP & R\&D/GDP & TET/GDP & ITRE & SUM6 & SUM15 & EPS & MBEPS & NMBEPS & LATENT6 & LATENT15 & BL_CO2 & BL_PCA \\
\hline \multirow[t]{2}{*}{$\log (\mathrm{Y} / \mathrm{P})$} & 0,788 & 1,210 & 1,530 & $-0,440$ & 1,685 & 0,731 & 0,925 & 0,583 & 0,635 & 0,605 & 0,702 & 0,874 & 0,733 & 0,724 \\
\hline & 2,444 & 3,850 & 5,964 & $-0,972$ & 1,352 & 2,333 & 3,120 & 1,809 & 1,937 & 1,874 & 2,325 & 3,091 & 2,335 & 2,169 \\
\hline$[\log (\mathrm{Y} / \mathrm{P})] 2$ & $-0,223$ & $-0,295$ & $-0,327$ & $-0,046$ & $-0,333$ & $-0,213$ & $-0,241$ & $-0,191$ & $-0,201$ & $-0,193$ & $-0,203$ & $-0,228$ & $-0,203$ & $-0,219$ \\
\hline \multirow{3}{*}{$\begin{array}{c}\text { Current EPS } \\
\text { Indicator }\end{array}$} & $-4,396$ & $-5,534$ & $-7,793$ & $-0,605$ & $-1,770$ & $-4,276$ & $-5,092$ & $-3,729$ & $-3,894$ & $-3,762$ & $-4,186$ & $-5,010$ & $-4,015$ & $-4,192$ \\
\hline & & $-0,0020$ & $-0,0036$ & 0,0067 & $-0,0276$ & $-0,0054$ & $-0,0129$ & $-0,0070$ & $-0,0029$ & $-0,0055$ & $-0,0094$ & $-0,0148$ & $-0,0113$ & 0,0009 \\
\hline & & $-0,546$ & $-1,519$ & 0,673 & $-6,911$ & $-2,596$ & $-5,175$ & $-2,041$ & $-1,255$ & $-1,975$ & $-3,180$ & $-5,790$ & $-2,487$ & 0,195 \\
\hline Adjusted $\mathrm{R}^{2}$ & 0,975 & 0,975 & 0,978 & 0,968 & 0,978 & 0,976 & 0,978 & 0,976 & 0,976 & 0,976 & 0,976 & 0,978 & 0,977 & 0,976 \\
\hline $\log \mathrm{L}$ & 558,510 & 386,538 & 531,399 & 380,330 & 388,196 & 562,369 & 573,973 & 561,888 & 559,983 & 561,158 & 565,157 & 576,207 & 533,998 & 530,201 \\
\hline$F$ test & 341,652 & 213,722 & 347,649 & 180,499 & 237,945 & 342,863 & 370,744 & 341,752 & 337,391 & 340,074 & 349,368 & 376,361 & 332,529 & 323,605 \\
\hline No obs. & 304 & 201 & 279 & 213 & 197 & 303 & 303 & 303 & 303 & 303 & 303 & 303 & 285 & 285 \\
\hline
\end{tabular}

\begin{tabular}{|c|c|c|c|c|c|c|c|c|c|c|c|c|c|c|}
\hline & \multicolumn{14}{|c|}{ TFEC/GDP } \\
\hline & & PACE/GDP & $\mathrm{R} \& \mathrm{D} / \mathrm{GDP}$ & TET/GDP & ITRE & SUM6 & SUM15 & EPS & MBEPS & NMBEPS & LATENT6 & LATENT15 & $\mathrm{BL} \_\mathrm{CO} 2$ & BL_PCA \\
\hline \multirow[t]{2}{*}{$\log (\mathrm{Y} / \mathrm{P})$} & 1,193 & 1,574 & 1,783 & 0,355 & 1,977 & 1,201 & 1,394 & 1,095 & 1,141 & 1,091 & 1,172 & 1,319 & 1,198 & 1,193 \\
\hline & $-4,600$ & 4,798 & 6,402 & 0,765 & 1,406 & 4,563 & 5,520 & 4,104 & 4,221 & 4,102 & 4,520 & 5,301 & 4,577 & 4,316 \\
\hline$[\log (\mathrm{Y} / \mathrm{P})] 2$ & $-0,289$ & $-0,356$ & $-0,372$ & $-0,174$ & $-0,397$ & $-0,289$ & $-0,316$ & $-0,273$ & $-0,281$ & $-0,271$ & $-0,281$ & $-0,301$ & $-0,279$ & $-0,292$ \\
\hline \multirow{4}{*}{$\begin{array}{l}\text { Current EPS } \\
\text { Indicator } \\
\text { Adjusted } \mathrm{R}^{2}\end{array}$} & $-6,729$ & $-6,005$ & $-7,953$ & $-2,221$ & $-1,878$ & $-6,640$ & $-7,546$ & $-6,271$ & $-6,396$ & $-6,176$ & $-6,514$ & $-7,241$ & $-6,274$ & $-6,442$ \\
\hline & & $-0,0013$ & $-0,0029$ & 0,0215 & $-0,0246$ & $-0,0045$ & $-0,0124$ & $-0,0044$ & $-0,0007$ & $-0,0050$ & $-0,0066$ & $-0,0123$ & $-0,0096$ & 0,0003 \\
\hline & & $-0,302$ & $-1,434$ & 2,331 & $-6,415$ & $-2,231$ & $-5,096$ & $-1,215$ & $-0,281$ & $-1,750$ & $-2,205$ & $-4,556$ & $-2,012$ & 0,065 \\
\hline & 0,975 & 0,969 & 0,976 & 0,965 & 0,971 & 0,975 & 0,977 & 0,975 & 0,975 & 0,975 & 0,975 & 0,977 & 0,976 & 0,976 \\
\hline $\log \mathrm{L}$ & 563,455 & 373,746 & 521,884 & 380,413 & 370,807 & 564,023 & 575,596 & 562,678 & 561,525 & 563,445 & 564,577 & 573,485 & 536,451 & 533,613 \\
\hline $\mathrm{F}$ test & 336,833 & 172,363 & 314,602 & 164,377 & 185,406 & 330,852 & 357,702 & 327,863 & 325,320 & 329,564 & 332,092 & 352,650 & 322,436 & 315,943 \\
\hline No obs. & 304 & 201 & 279 & 213 & 197 & 303 & 303 & 303 & 303 & 303 & 303 & 303 & 285 & 285 \\
\hline
\end{tabular}

Notes to the tables: a) coefficient estimates from FE estimation; b) country-year fixed effects and full set of time dummies included in all models; c) t-statistics from robust standard errors in italics. 
Table 5: Energy Efficiency Kuznets Relationship - Lagged Policy Indicators

\begin{tabular}{|c|c|c|c|c|c|c|c|c|c|c|c|c|c|}
\hline & \multicolumn{13}{|c|}{ TPES/GDP } \\
\hline & PACE/GDP & R\&D/GDP & TET/GDP & ITRE & SUM6 & SUM15 & EPS & MBEPS & NMBEPS & LATENT6 & LATENT15 & BL_CO2 & BL_PCA \\
\hline $\log (\mathrm{Y} / \mathrm{P})$ & 1,453 & 1,634 & $-0,441$ & 2,300 & 0,864 & 1,021 & 0,734 & 0,813 & 0,736 & 0,866 & 1,023 & 0,806 & 0,829 \\
\hline & 4,977 & 6,587 & $-0,880$ & 1,308 & 2,509 & 3,040 & 2,157 & 2,309 & 2,189 & 2,690 & 3,322 & 2,392 & 2,331 \\
\hline$[\log (\mathrm{Y} / \mathrm{P})] 2$ & $-0,328$ & $-0,342$ & $-0,046$ & $-0,420$ & $-0,233$ & $-0,255$ & $-0,212$ & $-0,227$ & $-0,211$ & $-0,228$ & $-0,251$ & $-0,211$ & $-0,229$ \\
\hline & $-6,396$ & $-8,180$ & $-0,550$ & $-1,601$ & $-4,279$ & $-4,813$ & $-3,952$ & $-4,111$ & $-3,943$ & $-4,409$ & $-5,088$ & $-3,891$ & $-4,140$ \\
\hline Lagged EPS & $-0,0031$ & $-0,0041$ & 0,0106 & $-0,0230$ & $-0,0034$ & $-0,0087$ & $-0,0077$ & $-0,0012$ & $-0,0084$ & $-0,0089$ & $-0,0130$ & $-0,0110$ & 0,0000 \\
\hline Indicator & $-0,907$ & $-1,562$ & 0,950 & $-4,977$ & $-1,639$ & $-3,409$ & $-2,388$ & $-0,543$ & $-3,438$ & $-3,291$ & $-5,161$ & $-2,657$ & 0,010 \\
\hline Adjusted $\mathrm{R}^{2}$ & 0,975 & 0,979 & 0,970 & 0,976 & 0,977 & 0,977 & 0,977 & 0,976 & 0,977 & 0,977 & 0,978 & 0,977 & 0,976 \\
\hline $\log \mathrm{L}$ & 371,517 & 506,954 & 364,321 & 361,328 & 536,842 & 541,975 & 538,959 & 535,650 & 540,931 & 540,819 & 548,411 & 539,444 & 535,444 \\
\hline $\mathrm{F}$ test & 208,236 & 340,846 & 177,369 & 210,934 & 329,721 & 342,066 & 334,758 & 326,917 & 339,520 & 339,246 & 358,187 & 335,924 & 326,434 \\
\hline No obs. & 189 & 261 & 199 & 184 & 285 & 285 & 285 & 285 & 285 & 285 & 285 & 285 & 285 \\
\hline
\end{tabular}

\begin{tabular}{|c|c|c|c|c|c|c|c|c|c|c|c|c|c|}
\hline & \multicolumn{13}{|c|}{ TFEC/GDP } \\
\hline & PACE/GDP & R\&D/GDP & TET/GDP & ITRE & SUM6 & SUM15 & EPS & MBEPS & NMBEPS & LATENT6 & LATENT15 & BL_CO2 & BL_PCA \\
\hline \multirow[t]{2}{*}{$\log (\mathrm{Y} / \mathrm{P})$} & 1,734 & 1,786 & 0,344 & 2,628 & 1,290 & 1,465 & 1,198 & 1,268 & 1,183 & 1,292 & 1,430 & 1,248 & 1,265 \\
\hline & 5,942 & 7,625 & 0,719 & 1,405 & 4,686 & 5,453 & 4,426 & 4,561 & 4,422 & 4,923 & 5,693 & 4,660 & 4,507 \\
\hline$[\log (\mathrm{Y} / \mathrm{P})] 2$ & $-0,379$ & $-0,375$ & $-0,170$ & $-0,492$ & $-0,303$ & $-0,328$ & $-0,289$ & $-0,301$ & $-0,285$ & $-0,300$ & $-0,319$ & $-0,287$ & $-0,301$ \\
\hline \multirow{4}{*}{$\begin{array}{l}\text { Lagged EPS } \\
\text { Indicator } \\
\text { Adjusted } \mathrm{R}^{2}\end{array}$} & $-6,800$ & $-8,955$ & $-2,084$ & $-1,771$ & $-6,587$ & $-7,275$ & $-6,424$ & $-6,543$ & $-6,318$ & $-6,727$ & $-7,463$ & $-6,260$ & $-6,459$ \\
\hline & $-0,0035$ & $-0,0035$ & 0,0286 & $-0,0170$ & $-0,0023$ & $-0,0090$ & $-0,0055$ & 0,0002 & $-0,0074$ & $-0,0064$ & $-0,0110$ & $-0,0084$ & 0,0004 \\
\hline & $-0,880$ & $-1,447$ & 3,192 & $-4,516$ & $-1,182$ & $-3,863$ & $-1,662$ & 0,073 & $-2,975$ & $-2,433$ & $-4,295$ & $-1,997$ & 0,098 \\
\hline & 0,971 & 0,978 & 0,969 & 0,970 & 0,977 & 0,978 & 0,977 & 0,977 & 0,978 & 0,977 & 0,978 & 0,977 & 0,977 \\
\hline $\log \mathrm{L}$ & 364,692 & 505,286 & 371,052 & 347,015 & 546,514 & 553,436 & 547,701 & 545,793 & 550,398 & 548,760 & 555,689 & 548,279 & 545,792 \\
\hline $\mathrm{F}$ test & 177,450 & 324,053 & 172,004 & 166,516 & 335,894 & 352,955 & 338,760 & 334,163 & 345,365 & 341,340 & 358,691 & 340,167 & 334,162 \\
\hline No obs. & 189 & 261 & 199 & 184 & 285 & 285 & 285 & 285 & 285 & 285 & 285 & 285 & 285 \\
\hline
\end{tabular}

Notes to the tables: see Table 4. 


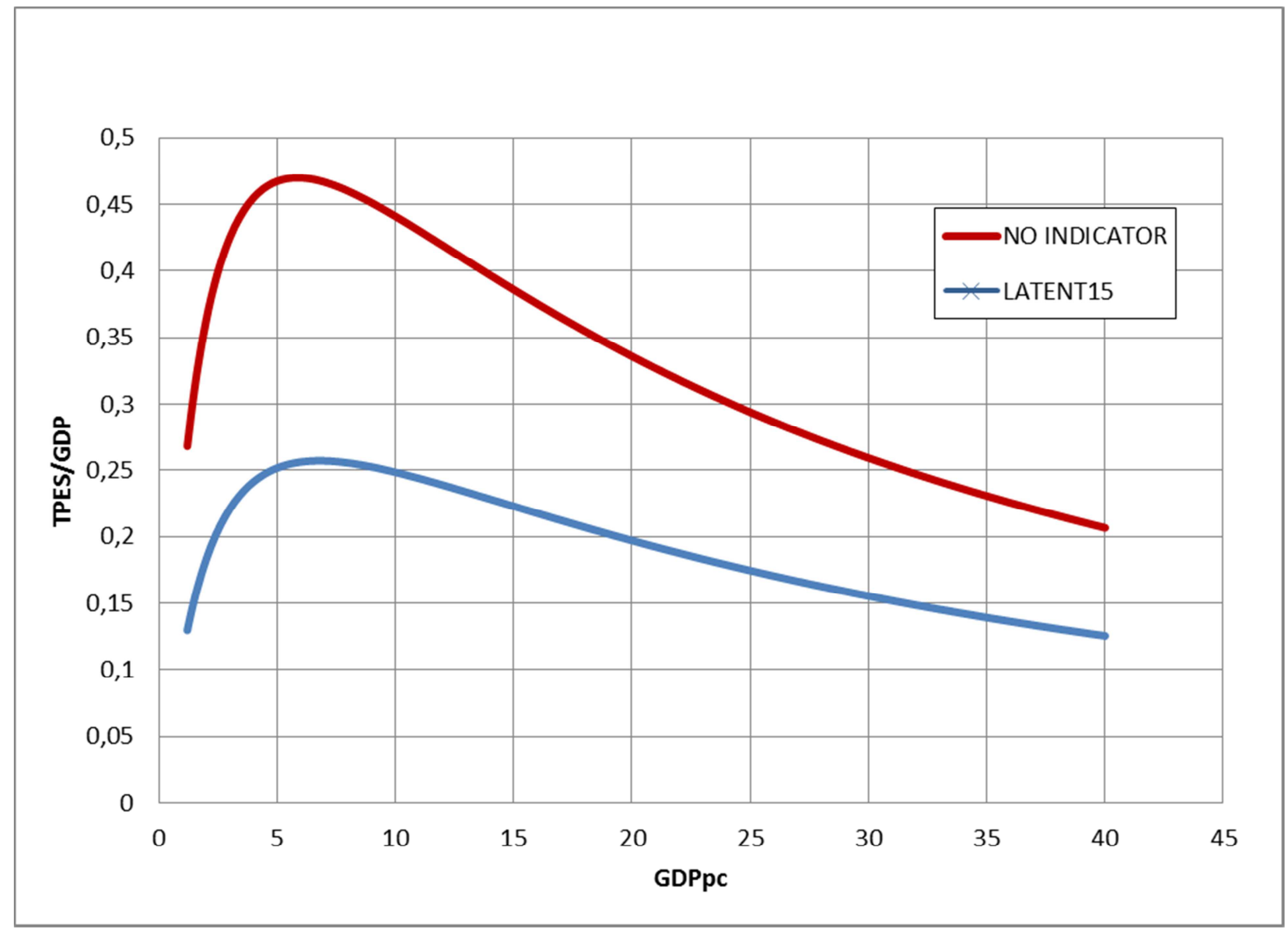

Specifically, the former suggest that environmental policy reduces the energy intensity of the economy, while the former suggest no such relationship. Furthermore, composite and emission based indicators generally provide a similar picture, suggesting that a 10 percent increase in policy commitment/stringency leads to a reduction of between 0.5 and 1.5 percent in energy intensity.

The analysis presented in the paper points to some fruitful future research directions. First, methodologies should be devised to appropriately summarize the several environmental policy indicators into one summary statistics for use in aggregate assessments of the impact of environmental policy on economic growth and performance. Second, attention should be devoted to the quantification of differences emerging from the various indicators. Thirdly, additional empirical applications should be considered. In this direction we are currently focusing our research efforts. 


\section{References}

Agras, J., Chapman, D., 1999. A dynamic approach to the environmental Kuznets curve hypothesis. Ecological Economics 28, 267-277.

Ambec, S., Cohen, M.A., Elgie, S., Lanoie, P. 2013. The Porter hypothesis at 20: can environmental regulation enhance innovation and competitiveness?. Review of Environmental Economics and Policy 7, 2-22

Berman, E., Bui, L. T. M., 2001. Environmental regulation and productivity: evidence from oil refineries. Review of Economics and Statistics 83 (3), 498-510.

Botta, E., Koźluk, T., 2014. Measuring environmental policy stringency in OECD countries: a composite index approach. OECD Economics Department Working Papers No. 1177, OECD Publishing, http://dx.doi.org/10.1787/5jxrjnc45gvg-en.

Brunel, C., Levinson, A., 2013. Measuring environmental regulatory stringency. OECD working paper 2013/05, OECD, doi:10.1787/18166881.

Cole, M., Elliot, R., 2003. Do environmental regulations influence trade patterns? testing old and new trade theories. The World Economy 26 (8), 1163-1186.

De Boeck, P., Wilson, M., 2004. A framework for item response models. In: Explanatory item response models. A generalized linear and nonlinear approach, eds. P. De Broeck and M. Wilson, New York: Springer, pp.3-41.

EUROSTAT 2015. Eurostat Database, available at http://ec.europa.eu/eurostat/data/database.

Fisher, C., Newell, R., 2008. Environmental and technology policies for climate mitigation. Journal of Environmental Economics and Management 55 (), 142-162.

Galeotti, M., Lanza, A., Pauli, F. 2006. Reassessing the Environmental Kuznets Curve for $\mathrm{CO}_{2}$ Emissions: A Robustness Exercise. Ecological Economics 57, 152-163.

Galeotti, M., Rubashkina, Y., Salini, S., Verdolini, E., 2014. Environmental Policy Performance and its Determinants: Application of a Three-level Random Intercept Model. FEEM Nota di Lavoro No. 2014.090.

Gray, W.B., Shadbegian R., 1993. Pollution Abatement Costs, Regulation, and Plant-Level Productivity. NBER Working Paper N. 4994.

IEA 2015. Energy Technology RD\&D Statistics Database, available at www.oecd.org.

Haščič, I., Johnstone N., Watson F., Kaminker C., 2010. Climate Policy and Technological Innovation and Transfer: An Overview of Trends and Recent Empirical Results. OECD Environment Working Papers 30, OECD Publishing.

Jaffe, A.B., S.R. Peterson, P.R. Portney, and R.N. Stavins, 1995. Environmental regulations and the competitiveness of U.S. manufacturing: what does the evidence tell us?. Journal of Economic Literature, 33, 132-163.

Jaffe, A., Palmer, K., 1997. Environmental regulation and innovation: a panel data study. Review of Economics and Statistics 79 (4), 610-619.

Judson, R.A., Schmalensee, R., Stoker, T.M., 1999. Economic development and the structure of demand for commercial energy. Energy Journal 20, 29-57.

Lanoie, P., Laurent-Lucchetti, J., Johnstone, N., Ambec S., 2011. Environmental policy, innovation and performance: new insights on the Porter hypothesis. Journal of Economics \& Management Strategy 20, 803-842. 
Levinson, A., Taylor S., 2004. Unmasking the pollution haven effect. International Economic Review 49(1), 223-254.

Lieb, C.M., 2003. The environmental Kuznets curve - A survey of the empirical evidence and of possible causes. University of Heidelberg, Department of Economics Discussion Paper Series No. 391.

Nesta, L., Vona, F., Nicolli, F., 2014. Environmental policies, competition and innovation in renewable energy. Journal of Environmental Economics and Management 67(3), 396-411.

Porter, M., 1991. America's green strategy. Scientific American 264, 168.

Porter, M.E., van der Linde, C., 1995. Towards a new conception of the environmentalcompetitiveness relationship. Journal of Economic Perspectives 9: 97-118.

Rubashkina, Y., Galeotti, M., Verdolini, E., 2015. Environmental regulation and competitiveness: empirical evidence on the Porter hypothesis from European manufacturing sectors. Energy Policy 83: 288-300.

Suri, V., Chapman, D., 1998. Economic growth, trade and energy: implications for the environmental Kuznets curve. Ecological Economics 25, 195-208.

Tobey, J., 1990. The effects of domestic environmental policies on patterns of world trade: an empirical test. Kyklos 43 (2), 191-209.

Vona, F., Nicolli, F., 2012. The evolution of renewable energy policy in OECD countries: aggregate indicators and d eterminants. FEEM Nota di Lavoro No. 2012/051.

WIOD, 2012. World Input-Output Database, February 2012 Release.

World Bank, 2013. The World Bank, World Development Indicators. 


\section{Appendix A: Composite Indicators}

Figure A.1: Time Profiles, SUM 15 vs SUM6 Composite Indicators, 1995-2009

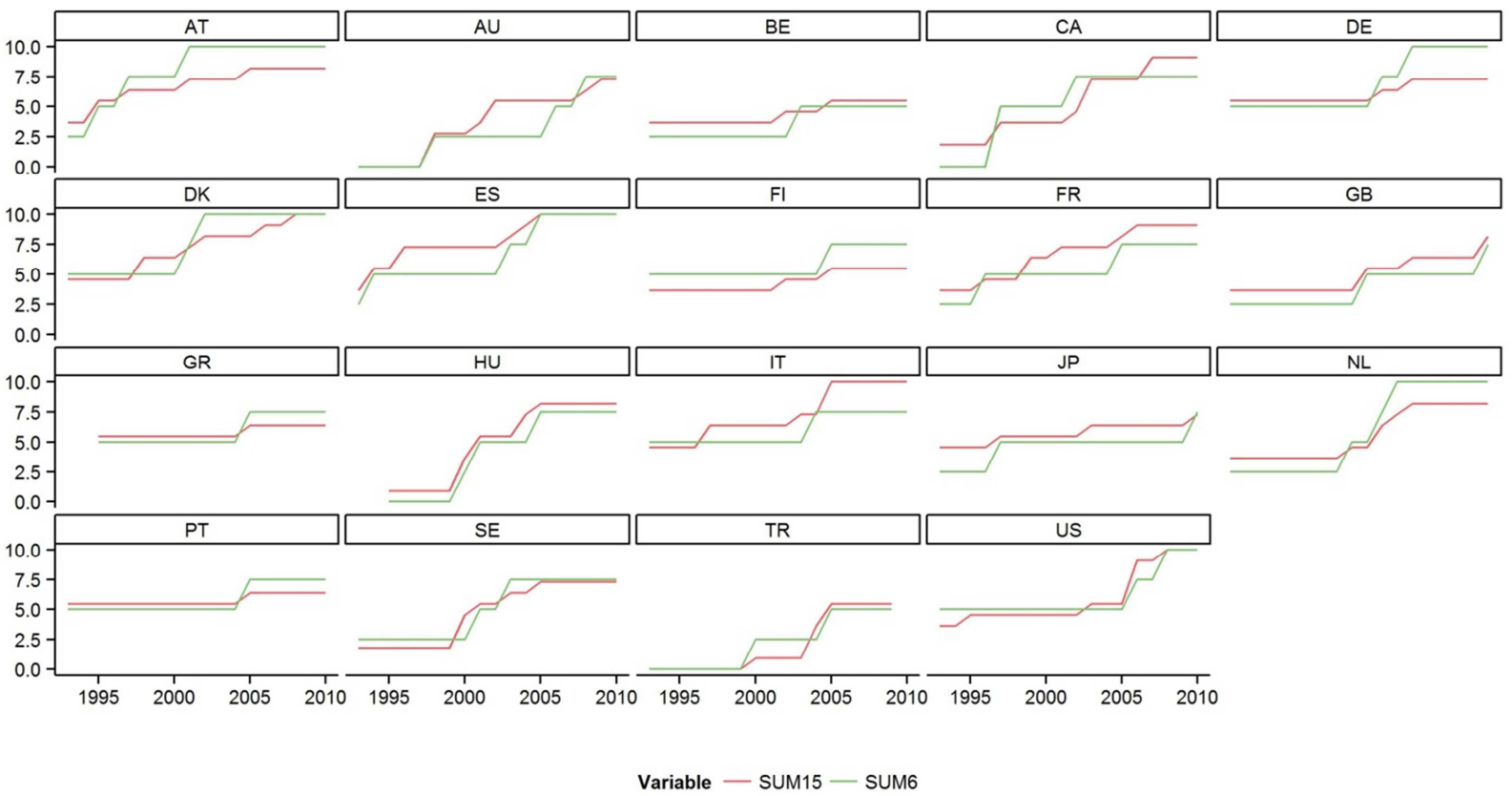

Figure A.2 Time Profiles, EPS, MBEPS and NMBEPS Composite Indicators, 1995-2009

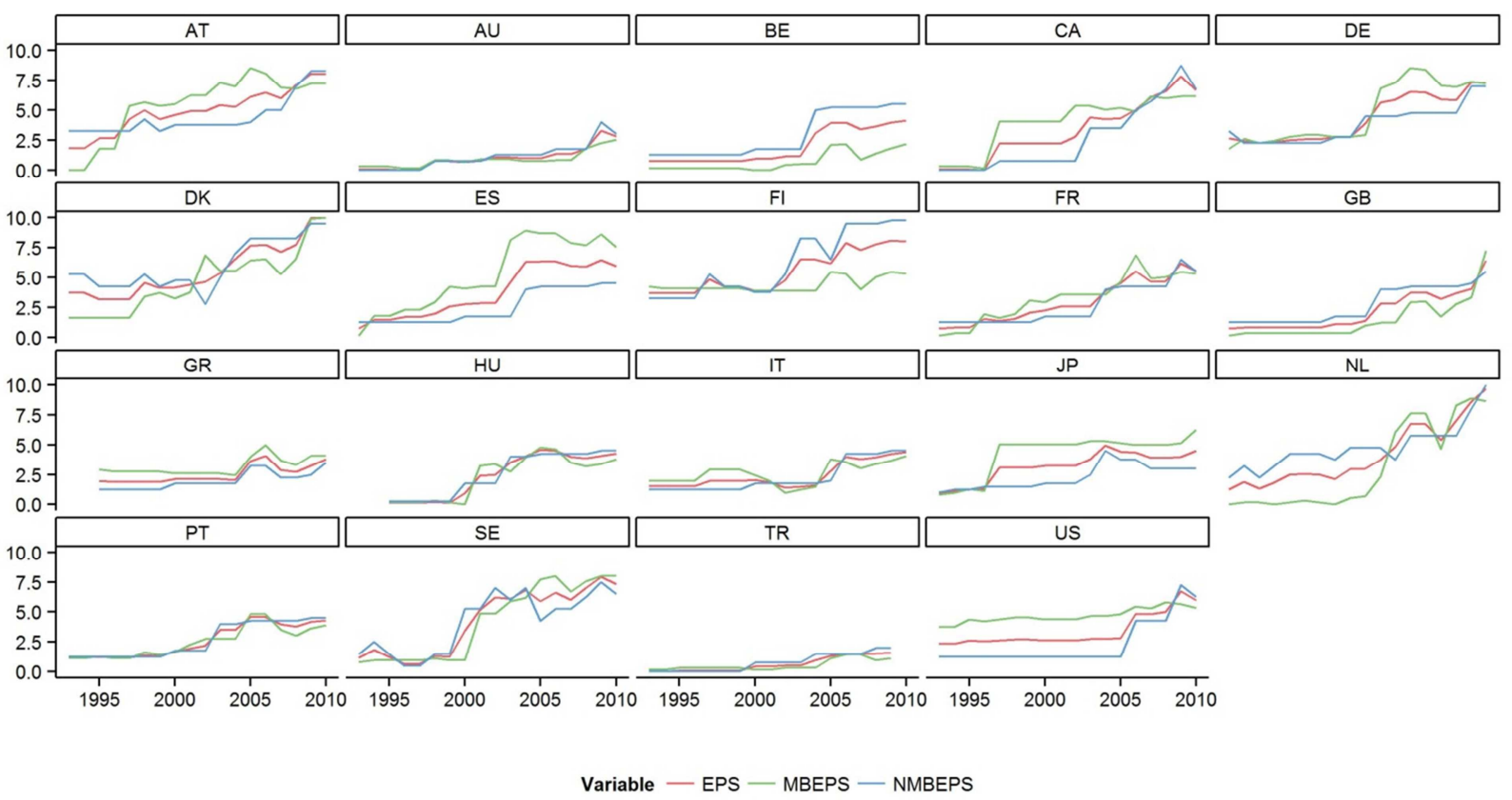

\section{Appendix B: Brunel and Levinson Composite Indicators for Pollutants Other than $\mathrm{CO}_{2}$}

Composite indicators as suggested by Brunel and Levinson (2013) (BL) were computed for the following pollutants, in addition to carbon dioxide for $\mathrm{SO}_{\mathrm{x}}, \mathrm{NO}_{\mathrm{x}}, \mathrm{NMVOC}, \mathrm{NH}_{3}, \mathrm{~N}_{2} \mathrm{O}, \mathrm{CO}, \mathrm{CH}_{4}$. 
Descriptive statistics are provided in Table B.1, while the correlation between the various indicators is presented in Table B.2.

Table B.1: Descriptive Statistics, BL Indicators

\begin{tabular}{|c|c|c|c|c|c|c|c|c|c|}
\hline Country & BL_EM & BL_CO2 & BL_SOX & BL_NOX & BL_NMVOC & BL_NH3 & BL_N2O & BL_CO & BL_CH4 \\
\hline Australia & 2.586 & 0.966 & 0.110 & 0.186 & 0.170 & 0.226 & 1.030 & 0.015 & 0.120 \\
\hline Austria & 8.290 & 6.249 & 9.097 & 2.662 & 3.604 & 1.274 & 1.763 & 1.166 & 1.435 \\
\hline Belgium & 3.834 & 2.912 & 1.902 & 1.235 & 3.149 & 0.263 & 0.562 & 0.716 & 0.688 \\
\hline Canada & 1.339 & 1.518 & 0.246 & 0.594 & 0.703 & 0.450 & 0.329 & 0.317 & 0.618 \\
\hline Denmark & 4.551 & 2.391 & 0.426 & 0.384 & 6.311 & 0.487 & 0.661 & 3.762 & 2.043 \\
\hline Finland & 1.846 & 2.401 & 1.369 & 1.070 & 3.481 & 2.864 & 1.280 & 1.750 & 1.365 \\
\hline France & 3.901 & 6.346 & 2.179 & 1.589 & 2.424 & 0.703 & 0.874 & 0.799 & 1.101 \\
\hline Germany & 4.735 & 3.167 & 2.918 & 1.772 & 2.200 & 0.406 & 0.855 & 1.905 & 1.013 \\
\hline Greece & 4.910 & 2.192 & 0.563 & 4.825 & 4.556 & 2.860 & 2.145 & 2.003 & 1.385 \\
\hline Hungary & 1.331 & 0.998 & 0.468 & 0.547 & 0.607 & 0.499 & 0.305 & 0.434 & 0.184 \\
\hline Italy & 6.717 & 3.939 & 1.732 & 1.469 & 2.762 & 1.435 & 1.998 & 1.621 & 1.351 \\
\hline Japan & 7.337 & 5.695 & 3.010 & 2.272 & 4.952 & 7.905 & 8.088 & 3.275 & 7.771 \\
\hline Netherlands & 2.747 & 2.502 & 2.573 & 1.323 & 6.515 & 1.463 & 1.196 & 2.725 & 1.507 \\
\hline Portugal & 4.365 & 2.475 & 0.427 & 0.565 & 0.792 & 1.327 & 1.185 & 0.833 & 0.237 \\
\hline Spain & 4.621 & 3.510 & 0.506 & 0.906 & 0.488 & 1.521 & 3.127 & 1.116 & 1.268 \\
\hline Sweden & 3.097 & 7.953 & 2.690 & 1.496 & 6.336 & 2.072 & 1.511 & 2.152 & 1.949 \\
\hline Turkey & 3.912 & 1.932 & 0.287 & 0.758 & 0.784 & 1.215 & 4.892 & 0.422 & 0.577 \\
\hline United Kingdom & 6.139 & 3.562 & 1.006 & 1.045 & 2.074 & 0.922 & 0.854 & 1.412 & 1.187 \\
\hline USA & 2.068 & 1.322 & 0.451 & 0.556 & 0.909 & 0.764 & 0.558 & 0.213 & 0.294 \\
\hline
\end{tabular}

Table B.2: Correlation among Brunel and Levinson Indicators

\begin{tabular}{|c|c|c|c|c|c|c|c|c|}
\hline & BL_CO2 & BL_SOX & BL_NOX & BL_NMVOC & BL_NH3 & BL_N2O & BL_CO & BL_CH4 \\
\hline BL_CO2 & 1 & & & & & & & \\
\hline BL_SOX & 0.642 & 1 & & & & & & \\
\hline$\overline{\text { BL_NOX }}$ & 0.3779 & 0.3785 & 1 & & & & & \\
\hline BL_NMVOC & 0.4925 & 0.3711 & 0.459 & 1 & & & & \\
\hline BL_NH3 & 0.3758 & 0.1889 & 0.3727 & 0.3866 & 1 & & & \\
\hline BL_N2O & 0.3042 & 0.1393 & 0.2509 & 0.1518 & 0.8228 & 1 & & \\
\hline BL_CO & 0.3316 & 0.1886 & 0.3581 & 0.7981 & 0.4398 & 0.2792 & 1 & \\
\hline BL_CH4 & 0.4864 & 0.2873 & 0.2983 & 0.5013 & 0.9085 & 0.7754 & 0.5675 & 1 \\
\hline
\end{tabular}

Looking at average values we see that there is a high heterogeneity of the indicators across countries, with most countries displaying mixed performance for the different indicators. Some of the BL indicators are highly correlated with each other. For instance, the indicator based on $\mathrm{CH}_{4}$ is highly correlated with those build on $\mathrm{NH}_{3}$ and $\mathrm{N}_{2} \mathrm{O}$. Conversely, the one based on $\mathrm{SO}_{\mathrm{x}}$ is poorly correlated with the one based on $\mathrm{N}_{2} \mathrm{O}$, indicating that these variables move in different directions within our sample. ${ }^{25}$ Both pollutants are in fact associated with combustion from fossil fuels in

\footnotetext{
${ }^{25}$ Sulfur dioxide $\left(\mathrm{SO}_{2}\right)$ is one of a group of highly reactive gasses known as "oxides of sulfur." According to the EPA, the largest sources of $\mathrm{SO}_{2}$ emissions in the USA are from fossil fuel combustion at power plants (around 73\%) and other industrial facilities (20\%). Smaller sources of $\mathrm{SO}_{2}$ emissions include industrial processes such as extracting metal from ore and the burning of high sulfur containing fuels by locomotives, large ships, and non-road equipment. $\mathrm{SO}_{2}$ is linked with a number of adverse effects on the respiratory system. Nitrogen Oxides $\left(\mathrm{NO}_{\mathrm{x}}\right)$ are a family of poisonous, highly reactive gases. These gases form when fuel is burned at high temperatures. $\mathrm{NO}_{\mathrm{x}}$ pollution is emitted by automobiles, trucks and various non-road vehicles (e.g., construction equipment, boats, etc.) as well as industrial sources such as power plants, industrial boilers, cement kilns, and turbines. NOx often appears as a brownish gas. It is
} 
industrial plants. However, a great share of $\mathrm{SO}_{\mathrm{x}}$ is associated with exhaust gases from the transport sector, unlike $\mathrm{SO}_{2}$. Hence, the low correlation of these two indicators seems to suggest that countries which are successful at regulating one sector (industry) may not necessarily be good at regulating another one (transport). This preliminary comparison between emission-based indicators points to the fact that the problem of multidimensionality highlighted in Brunel and Levinson (2013) is a deeply-rooted problem, even within the same class of indicators.

We conduct a principal component analysis (PCA) of the various emission-based BL indicators to explore whether they can be successfully summarized by a synthetic statistics. As said in the text, PCA allows reducing a number of (possibly) correlated variables (representing as many characteristics of the analyzed phenomenon) to a (smaller) number of latent variables called principal components. The first principal component accounts for as much of the variability in the data as possible and each subsequent component accounts for as much of the remaining variability as possible.

Table B.3 shows the principal component eigenvalues and the principal component eigenvectors in the left and right panel, respectively.

Table B. 3: Principal Component Analysis on Brunel and Levinson Emission-based Indicators

\begin{tabular}{|c|c|c|c|c|c|c|c|c|}
\hline \multicolumn{2}{|c|}{ Component Eigenvalue } & Difference & Proportion & Cumulative & Variable & Comp1 & Comp2 & Comp3 \\
\hline Comp1 & 4.06045 & 2.5701 & 0.5076 & 0.5076 & BL_CO2 & 0.3402 & 0.3085 & 0.3832 \\
\hline Comp2 & 1.49036 & 0.441324 & 0.1863 & 0.6939 & BL_SOX & 0.2551 & 0.4461 & 0.5171 \\
\hline Comp3 & 1.04903 & 0.368664 & 0.1311 & 0.825 & BL_NOX & 0.2901 & 0.2612 & 0.0334 \\
\hline Comp4 & 0.680367 & 0.356164 & 0.085 & 0.91 & BL_NMVOC & 0.3622 & 0.342 & -0.4364 \\
\hline Comp5 & 0.324203 & 0.125444 & 0.0405 & 0.9506 & BL_NH3 & 0.4116 & -0.3981 & 0.0502 \\
\hline Comp6 & 0.198758 & 0.0606278 & 0.0248 & 0.9754 & BL_N2O & 0.3414 & -0.5039 & 0.2101 \\
\hline Comp7 & 0.138131 & 0.079427 & 0.0173 & 0.9927 & BL_CO & 0.3528 & 0.1382 & -0.5895 \\
\hline Comp8 & 0.0587036 & . & 0.0073 & 1 & BL_CH4 & 0.4397 & -0.2985 & 0.0037 \\
\hline
\end{tabular}

The left panel indicates that there are 3 significant principal components to be considered, since they exceed unity according to the usual rule of thumb. These three components together explain over $80 \%$ of the total variance. Form the right panel we see that the first component eigenvector is positively correlated with the all indicators, while the second explains prevalently the indicators for energy intensity, $\mathrm{CO}_{2}, \mathrm{NO}_{\mathrm{x}}$ and $\mathrm{SO}_{\mathrm{x}}$ emissions and is negatively correlated with the others. Consistent with the correlation table shown above, $\mathrm{N}_{2} \mathrm{O}$ and $\mathrm{SO}_{\mathrm{x}}$ are associated with a positive value in the first component and a negative and positive value, respectively, in the second component. This is consistent with the remark that the two indicators do not necessarily vary in 
the same direction, as explained above. The results of the PCA confirm that the creation of a single indicator summarizing the information for the different pollutants is not entirely possible. This is a first indication that even emission-based indexes may be plagued by issues of multidimensionality.

\section{Appendix C: Dendogram for Country Clustering}

Figure 6 in the text visualizes how the various indicators considered in this paper tend to cluster together. Figure A.3 presents analogous evidence for the different countries in our sample. Specifically, in the dendogram each country is positioned according to its distance with other countries. Countries with higher similarity cluster into nodes. The height indicates how far away the countries within the different clusters are. Specifically, the height of each node in the plot is proportional to the value of the intergroup dissimilarity between its two whiskers.

\section{Figure C.1: Dendogram for Different Countries}

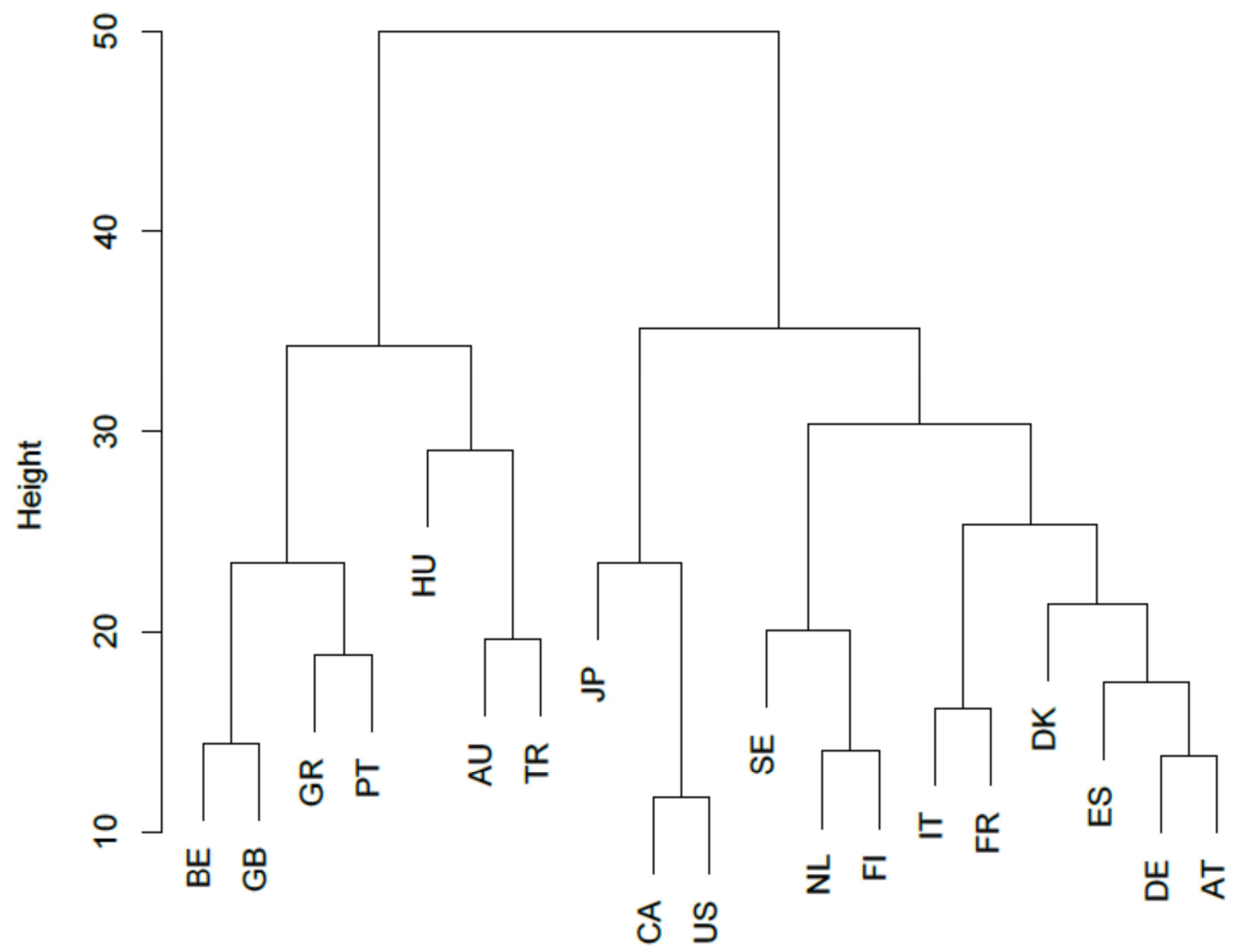




\section{Appendix D: Additional Empirical Results}

Table D.1: Per Capita Energy Kuznets Relationship - Current Policy Indicators

\begin{tabular}{|c|c|c|c|c|c|c|c|c|c|c|c|c|c|}
\hline \multicolumn{14}{|c|}{ TPES/POP } \\
\hline NOT & PACE/GDP & $\mathrm{R} \& \mathrm{D} / \mathrm{GDP}$ & TET/GDP & ITRE & SUM6 & SUM15 & EPS & MBEPS & NMBEPS & LATENT6 & LATENT15 & BL_CO2 & BL_PCA \\
\hline 1,788 & 2,210 & 2,530 & 0,560 & 2,685 & 1,731 & 1,925 & 1,583 & 1,635 & 1,605 & 1,702 & 1,874 & 1,733 & 1,193 \\
\hline 5,544 & 7,031 & 9,862 & 1,236 & 2,155 & 5,522 & 6,493 & 4,911 & 4,987 & 4,969 & 5,636 & 6,627 & 5,522 & 4,316 \\
\hline$-0,223$ & $-0,295$ & $-0,327$ & $-0,046$ & $-0,333$ & $-0,213$ & $-0,241$ & $-0,191$ & $-0,201$ & $-0,193$ & $-0,203$ & $-0,228$ & $-0,203$ & $-0,292$ \\
\hline \multirow[t]{3}{*}{$-4,396$} & $-5,534$ & $-7,793$ & $-0,605$ & $-1,770$ & $-4,276$ & $-5,092$ & $-3,729$ & $-3,894$ & $-3,762$ & $-4,186$ & $-5,009$ & $-4,015$ & $-6,442$ \\
\hline & $-0,0020$ & $-0,0036$ & 0,0067 & $-0,0276$ & $-0,0054$ & $-0,0129$ & $-0,0070$ & $-0,0029$ & $-0,0055$ & $-0,0094$ & $-0,0148$ & $-0,0113$ & 0,0003 \\
\hline & $-0,546$ & $-1,519$ & 0,673 & $-6,911$ & $-2,596$ & $-5,175$ & $-2,041$ & $-1,255$ & $-1,975$ & $-3,180$ & $-5,790$ & $-2,487$ & 0,0652 \\
\hline 0,992 & 0,992 & 0,993 & 0,979 & 0,984 & 0,992 & 0,993 & 0,992 & 0,992 & 0,992 & 0,992 & 0,993 & 0,992 & 0,976 \\
\hline 558,510 & 386,538 & 531,399 & 380,330 & 388,196 & 562,369 & 573,973 & 561,888 & 559,983 & 561,158 & 565,157 & 576,207 & 533,998 & 533,613 \\
\hline 1048,800 & 689,231 & 1066,598 & 274,303 & 337,572 & 1037,662 & 1120,849 & 1034,348 & 1021,334 & 1029,341 & 1057,072 & 1137,611 & 1023,040 & 315,943 \\
\hline 304 & 201 & 279 & 213 & 197 & 303 & 303 & 303 & 303 & 303 & 303 & 303 & 285 & 285,000 \\
\hline
\end{tabular}

\begin{tabular}{|c|c|c|c|c|c|c|c|c|c|c|c|c|c|c|}
\hline & \multicolumn{14}{|c|}{ TFEC/POP } \\
\hline & & PACE/GDP & R\&D/GDP & TET/GDP & ITRE & SUM6 & SUM15 & EPS & MBEPS & NMBEPS & LATENT6 & LATENT15 & BL_CO2 & BL_PCA \\
\hline $\log (\mathrm{Y} / \mathrm{P})$ & 2,193 & 2,574 & 2,783 & 1,355 & 2,977 & 2,201 & 2,394 & 2,095 & 2,141 & 2,091 & 2,172 & 2,319 & 2,198 & 2,193 \\
\hline & 8,457 & 7,848 & 9,993 & 2,920 & 2,117 & 8,361 & 9,480 & 7,851 & 7,920 & 7,863 & 8,377 & 9,318 & 8,397 & 7,936 \\
\hline$[\log (\mathrm{Y} / \mathrm{P})] 2$ & $-0,289$ & $-0,356$ & $-0,372$ & $-0,174$ & $-0,397$ & $-0,289$ & $-0,316$ & $-0,273$ & $-0,281$ & $-0,271$ & $-0,281$ & $-0,301$ & $-0,279$ & $-0,292$ \\
\hline & $-6,729$ & $-6,005$ & $-7,953$ & $-2,221$ & $-1,878$ & $-6,640$ & $-7,546$ & $-6,271$ & $-6,396$ & $-6,176$ & $-6,514$ & $-7,241$ & $-6,274$ & $-6,442$ \\
\hline Current EPS & & $-0,0013$ & $-0,0029$ & 0,0215 & $-0,0246$ & $-0,0045$ & $-0,0124$ & $-0,0044$ & $-0,0007$ & $-0,0050$ & $-0,0066$ & $-0,0123$ & $-0,0096$ & 0,0003 \\
\hline Indicator & & $-0,302$ & $-1,434$ & 2,331 & $-6,415$ & $-2,231$ & $-5,096$ & $-1,215$ & $-0,281$ & $-1,750$ & $-2,205$ & $-4,556$ & $-2,012$ & 0,065 \\
\hline Adjusted $\mathrm{R}^{2}$ & 0,992 & 0,990 & 0,992 & 0,978 & 0,980 & 0,992 & 0,992 & 0,992 & 0,991 & 0,992 & 0,992 & 0,992 & 0,992 & 0,992 \\
\hline $\log \mathrm{L}$ & 563,455 & 373,746 & 521,884 & 380,413 & 370,807 & 564,023 & 575,596 & 562,678 & 561,525 & 563,445 & 564,577 & 573,485 & 536,451 & 533,613 \\
\hline F test & 1027,537 & 566,665 & 938,588 & 268,483 & 265,112 & 995,001 & 1074,573 & 986,142 & 978,606 & 991,183 & 998,676 & 1059,600 & 986,597 & 967,009 \\
\hline No obs. & 304 & 201 & 279 & 213 & 197 & 303 & 303 & 303 & 303 & 303 & 303 & 303 & 285 & 285 \\
\hline
\end{tabular}

Notes: see notes to Table 4 in main text. 
Table D.2: Per Capita Energy Energy Kuznets Relationship - Lagged Policy Indicators

\begin{tabular}{|c|c|c|c|c|c|c|c|c|c|c|c|c|c|}
\hline & \multicolumn{13}{|c|}{ TPES/POP } \\
\hline & PACE/GDP & $\mathrm{R} \& \mathrm{D} / \mathrm{GDP}$ & TET/GDP & ITRE & SUM6 & SUM15 & EPS & MBEPS & NMBEPS & LATENT6 & LATENT15 & BL_CO2 & BL_PCA \\
\hline $\log (\mathrm{Y} / \mathrm{P})$ & 2,453 & 2,634 & 0,559 & 3,301 & 1,864 & 2,021 & 1,734 & 1,813 & 1,736 & 1,866 & 2,023 & 1,806 & 1,829 \\
\hline & 8,403 & 10,618 & 1,118 & 1,877 & 5,413 & 6,018 & 5,097 & 5,148 & 5,163 & 5,797 & 6,569 & 5,360 & 5,141 \\
\hline$[\log (\mathrm{Y} / \mathrm{P})] 2$ & $-0,328$ & $-0,342$ & $-0,046$ & $-0,420$ & $-0,233$ & $-0,255$ & $-0,212$ & $-0,227$ & $-0,211$ & $-0,228$ & $-0,251$ & $-0,211$ & $-0,229$ \\
\hline & $-6,396$ & $-8,180$ & $-0,550$ & $-1,601$ & $-4,279$ & $-4,813$ & $-3,952$ & $-4,111$ & $-3,943$ & $-4,409$ & $-5,088$ & $-3,891$ & $-4,140$ \\
\hline Lagged EPS & $-0,0031$ & $-0,0041$ & 0,0106 & $-0,0230$ & $-0,0034$ & $-0,0087$ & $-0,0077$ & $-0,0012$ & $-0,0084$ & $-0,0089$ & $-0,0130$ & $-0,0110$ & 0,0000 \\
\hline Indicator & $-0,907$ & $-1,562$ & 0,950 & $-4,977$ & $-1,639$ & $-3,409$ & $-2,388$ & $-0,543$ & $-3,438$ & $-3,291$ & $-5,161$ & $-2,657$ & 0,010 \\
\hline Adjusted $\mathrm{R}^{2}$ & 0,993 & 0,993 & 0,980 & 0,983 & 0,992 & 0,993 & 0,992 & 0,992 & 0,993 & 0,993 & 0,993 & 0,992 & 0,992 \\
\hline $\log \mathrm{L}$ & 371,517 & 506,954 & 364,321 & 361,328 & 536,842 & 541,975 & 538,959 & 535,650 & 540,931 & 540,819 & 548,411 & 539,444 & 535,444 \\
\hline F test & 700,101 & 1070,924 & 274,795 & 302,525 & 1024,675 & 1062,508 & 1040,112 & 1016,082 & 1054,706 & 1053,866 & 1111,913 & 1043,685 & 1014,604 \\
\hline No obs. & 189 & 261 & 199 & 184 & 285 & 285 & 285 & 285 & 285 & 285 & 285 & 285 & 285 \\
\hline
\end{tabular}

\begin{tabular}{|c|c|c|c|c|c|c|c|c|c|c|c|c|c|}
\hline & \multicolumn{13}{|c|}{ TFEC/POP } \\
\hline & PACE/GDP & $\mathrm{R} \& \mathrm{D} / \mathrm{GDP}$ & TET/GDP & ITRE & SUM6 & SUM15 & EPS & MBEPS & NMBEPS & LATENT6 & LATENT15 & BL_CO2 & BL_PCA \\
\hline \multirow[t]{2}{*}{$\log (\mathrm{Y} / \mathrm{P})$} & 2,734 & 2,786 & 1,344 & 3,628 & 2,290 & 2,465 & 2,198 & 2,268 & 2,183 & 2,292 & 2,430 & 2,248 & 2,265 \\
\hline & 9,369 & 11,895 & 2,810 & 1,940 & 8,318 & 9,176 & 8,121 & 8,157 & 8,160 & 8,733 & 9,675 & 8,393 & 8,071 \\
\hline$[\log (\mathrm{Y} / \mathrm{P})] 2$ & $-0,379$ & $-0,375$ & $-0,170$ & $-0,492$ & $-0,303$ & $-0,328$ & $-0,289$ & $-0,301$ & $-0,285$ & $-0,300$ & $-0,319$ & $-0,287$ & $-0,301$ \\
\hline \multirow{3}{*}{$\begin{array}{l}\text { Lagged EPS } \\
\text { Indicator }\end{array}$} & $-6,800$ & $-8,955$ & $-2,084$ & $-1,771$ & $-6,587$ & $-7,275$ & $-6,424$ & $-6,543$ & $-6,318$ & $-6,727$ & $-7,463$ & $-6,260$ & $-6,459$ \\
\hline & $-0,0035$ & $-0,0035$ & 0,0286 & $-0,0170$ & $-0,0023$ & $-0,0090$ & $-0,0055$ & 0,0002 & $-0,0074$ & $-0,0064$ & $-0,0110$ & $-0,0084$ & 0,0004 \\
\hline & $-0,880$ & $-1,447$ & 3,192 & $-4,516$ & $-1,182$ & $-3,863$ & $-1,662$ & 0,073 & $-2,975$ & $-2,433$ & $-4,295$ & $-1,997$ & 0,098 \\
\hline Adjusted $\mathrm{R}^{2}$ & 0,991 & 0,993 & 0,981 & 0,979 & 0,992 & 0,993 & 0,993 & 0,992 & 0,993 & 0,993 & 0,993 & 0,993 & 0,992 \\
\hline $\log \mathrm{L}$ & 364,692 & 505,286 & 371,052 & 347,015 & 546,514 & 553,436 & 547,701 & 545,793 & 550,398 & 548,760 & 555,689 & 548,279 & 545,792 \\
\hline $\mathrm{F}$ test & 607,450 & 992,732 & 285,780 & 240,886 & 1037,786 & 1089,780 & 1046,521 & 1032,511 & 1066,648 & 1054,382 & 1107,263 & 1050,808 & 1032,508 \\
\hline No obs. & 189 & 261 & 199 & 184 & 285 & 285 & 285 & 285 & 285 & 285 & 285 & 285 & 285 \\
\hline
\end{tabular}

Notes: see notes to Table 4 in main text. 
Table D.3: Energy Efficiency Kuznets Relationship - Additional Policy Indicators- Current and Lagged

\begin{tabular}{|c|c|c|c|c|c|c|c|}
\hline & \multicolumn{7}{|c|}{ TPES/GDP } \\
\hline & BL_SOX & BL_NOX & BL_NMVOC & BL_NH3 & BL_N2O & BL_CO & BL_CH4 \\
\hline $\log (\mathrm{Y} / \mathrm{P})$ & 0,743 & 0,689 & 0,736 & 0,739 & 0,481 & 0,729 & 0,715 \\
& 2,288 & 2,077 & 2,229 & 2,221 & 1,344 & 2,190 & 2,148 \\
\hline $\log (\mathrm{Y} / \mathrm{P})] 2$ & $-0,219$ & $-0,222$ & $-0,222$ & $-0,218$ & $-0,184$ & $-0,218$ & $-0,210$ \\
& $-4,267$ & $-4,269$ & $-4,241$ & $-4,153$ & $-3,343$ & $-4,175$ & $-3,965$ \\
Current EPS & $-0,0060$ & 0,0082 & 0,0019 & $-0,0051$ & 0,0111 & $-0,0003$ & $-0,0097$ \\
Indicator & $-1,218$ & 2,350 & 0,604 & $-0,817$ & 1,865 & $-0,095$ & $-1,363$ \\
Adjusted R & 0,976 & 0,977 & 0,976 & 0,976 & 0,977 & 0,976 & 0,976 \\
Log L & 530,798 & 532,913 & 530,392 & 530,444 & 532,510 & 530,188 & 531,024 \\
F test & 324,991 & 329,953 & 324,048 & 324,168 & 329,003 & 323,575 & 325,519 \\
No obs. & 285 & 285 & 285 & 285 & 285 & 285 & 285 \\
\hline
\end{tabular}

\begin{tabular}{|c|c|c|c|c|c|c|c|}
\hline & \multicolumn{7}{|c|}{ TFEC/GDP } \\
\hline & BL_SOX & BL_NOX & BL_NMVOC & BL_NH3 & BL_N2O & BL_CO & BL_CH4 \\
\hline \multirow[t]{2}{*}{$\log (\mathrm{Y} / \mathrm{P})$} & 1,205 & 1,153 & 1,198 & 1,206 & 1,053 & 1,196 & 1,181 \\
\hline & 4,433 & 4,256 & 4,347 & 4,379 & 3,280 & 4,326 & 4,315 \\
\hline$[\log (\mathrm{Y} / \mathrm{P})] 2$ & $-0,292$ & $-0,296$ & $-0,294$ & $-0,291$ & $-0,272$ & $-0,291$ & $-0,283$ \\
\hline \multirow{4}{*}{$\begin{array}{l}\text { Current EPS } \\
\text { Indicator } \\
\text { Adjusted } \mathrm{R}^{2}\end{array}$} & $-6,506$ & $-6,583$ & $-6,403$ & $-6,446$ & $-5,369$ & $-6,434$ & $-6,241$ \\
\hline & $-0,0045$ & 0,0085 & 0,0011 & $-0,0054$ & 0,0063 & $-0,0009$ & $-0,0096$ \\
\hline & $-0,759$ & 2,360 & 0,382 & $-0,769$ & 1,194 & $-0,367$ & $-1,152$ \\
\hline & 0,976 & 0,976 & 0,976 & 0,976 & 0,976 & 0,976 & 0,976 \\
\hline $\log \mathrm{L}$ & 533,955 & 536,680 & 533,677 & 533,916 & 534,380 & 533,644 & 534,441 \\
\hline$F$ test & 316,719 & 322,966 & 316,087 & 316,630 & 317,685 & 316,012 & 317,824 \\
\hline No obs. & 285 & 285 & 285 & 285 & 285 & 285 & 285 \\
\hline
\end{tabular}

\begin{tabular}{|c|c|c|c|c|c|c|c|}
\hline & \multicolumn{7}{|c|}{ TPES/GDP } \\
\hline & BL_SOX & BL_NOX & BL_NMVOC & BL_NH3 & BL_N2O & BL_CO & BL_CH4 \\
\hline $\log (\mathrm{Y} / \mathrm{P})$ & 0,846 & 0,816 & 0,845 & 0,836 & 0,591 & 0,829 & 0,808 \\
& 2,429 & 2,296 & 2,392 & 2,350 & 1,570 & 2,339 & 2,269 \\
{$[\log (\mathrm{Y} / \mathrm{P})] 2$} & $-0,231$ & $-0,233$ & $-0,235$ & $-0,229$ & $-0,197$ & $-0,229$ & $-0,219$ \\
& $-4,217$ & $-4,214$ & $-4,225$ & $-4,104$ & $-3,383$ & $-4,139$ & $-3,895$ \\
Lagged EPS & $-0,0063$ & 0,0046 & 0,0022 & $-0,0037$ & 0,0116 & 0,0001 & $-0,0104$ \\
Indicator & $-1,239$ & 1,355 & 0,807 & $-0,672$ & 1,920 & 0,034 & $-1,502$ \\
Adjusted R $\mathrm{R}^{2}$ & 0,976 & 0,976 & 0,976 & 0,976 & 0,977 & 0,976 & 0,977 \\
Log L & 536,135 & 536,352 & 535,720 & 535,594 & 538,261 & 535,445 & 536,474 \\
F test & 328,053 & 328,565 & 327,080 & 326,786 & 333,090 & 326,436 & 328,851 \\
No obs. & 285 & 285 & 285 & 285 & 285 & 285 & 285 \\
\hline
\end{tabular}




\begin{tabular}{|c|c|c|c|c|c|c|c|}
\hline & \multicolumn{7}{|c|}{ TFEC/GDP } \\
\hline & BL_SOX & BL_NOX & BL_NMVOC & BL_NH3 & BL_N2O & BL_CO & BL_CH4 \\
\hline \multirow[t]{2}{*}{$\log (\mathrm{Y} / \mathrm{P})$} & 1,275 & 1,247 & 1,279 & 1,272 & 1,145 & 1,267 & 1,250 \\
\hline & 4,597 & 4,480 & 4,559 & 4,528 & 3,553 & 4,515 & 4,480 \\
\hline$[\log (\mathrm{Y} / \mathrm{P})] 2$ & $-0,302$ & $-0,306$ & $-0,306$ & $-0,300$ & $-0,284$ & $-0,301$ & $-0,294$ \\
\hline \multirow{4}{*}{$\begin{array}{l}\text { Lagged EPS } \\
\text { Indicator } \\
\text { Adjusted } \mathrm{R}^{2}\end{array}$} & $-6,510$ & $-6,556$ & $-6,459$ & $-6,447$ & $-5,509$ & $-6,444$ & $-6,259$ \\
\hline & $-0,0035$ & 0,0065 & 0,0019 & $-0,0034$ & 0,0058 & $-0,0009$ & $-0,0075$ \\
\hline & $-0,623$ & 2,063 & 0,721 & $-0,511$ & 1,139 & $-0,347$ & $-0,944$ \\
\hline & 0,977 & 0,977 & 0,977 & 0,977 & 0,977 & 0,977 & 0,977 \\
\hline $\log \mathrm{L}$ & 546,015 & 547,714 & 546,004 & 545,923 & 546,557 & 545,823 & 546,355 \\
\hline F test & 334,696 & 338,793 & 334,670 & 334,475 & 335,998 & 334,236 & 335,511 \\
\hline No obs. & 285 & 285 & 285 & 285 & 285 & 285 & 285 \\
\hline
\end{tabular}

Notes: see notes to Table 4 in main text.

Table D.4: per Capita Energy Kuznets Relationship - Additional Policy Indicators- Current and Lagged

\begin{tabular}{|c|c|c|c|c|c|c|c|}
\hline & \multicolumn{7}{|c|}{ TPES/POP } \\
\hline & BL_SOX & BL_NOX & BL_NMVOC & BL_NH3 & BL_N2O & BL_CO & BL_CH4 \\
\hline $\log (\mathrm{Y} / \mathrm{P})$ & 1,743 & 1,689 & 1,736 & 1,739 & 1,481 & 1,729 & 1,715 \\
& 5,367 & 5,091 & 5,257 & 5,226 & 4,138 & 5,194 & 5,153 \\
{$[\log (\mathrm{Y} / \mathrm{P})] 2$} & $-0,219$ & $-0,222$ & $-0,222$ & $-0,218$ & $-0,184$ & $-0,218$ & $-0,210$ \\
& $-4,267$ & $-4,269$ & $-4,241$ & $-4,153$ & $-3,343$ & $-4,175$ & $-3,965$ \\
& $-0,0060$ & 0,0082 & 0,0019 & $-0,0051$ & 0,0111 & $-0,0003$ & $-0,0097$ \\
Current EPS & $-1,218$ & 2,350 & 0,604 & $-0,817$ & 1,865 & $-0,095$ & $-1,363$ \\
Indicator & 0,992 & 0,992 & 0,992 & 0,992 & 0,992 & 0,992 & 0,992 \\
Adjusted R ${ }^{2}$ & 530,798 & 532,913 & 530,392 & 530,444 & 532,510 & 530,189 & 531,024 \\
Log L & 1000,165 & 1015,224 & 997,305 & 997,669 & 1012,339 & 995,870 & 1001,769 \\
F test & 285 & 285 & 285 & 285 & 285 & 285 & 285 \\
\hline No obs. & 285 \\
\hline
\end{tabular}

\begin{tabular}{|c|c|c|c|c|c|c|c|}
\hline & \multicolumn{7}{|c|}{ TFEC/POP } \\
\hline & BL_SOX & BL_NOX & BL_NMVOC & BL_NH3 & BL_N2O & BL_CO & BL_CH4 \\
\hline $\log (\mathrm{Y} / \mathrm{P})$ & 2,205 & 2,153 & 2,198 & 2,206 & 2,053 & 2,196 & 2,181 \\
& 8,110 & 7,946 & 7,974 & 8,010 & 6,395 & 7,942 & 7,969 \\
\hline $\log (\mathrm{Y} / \mathrm{P})] 2$ & $-0,292$ & $-0,296$ & $-0,294$ & $-0,291$ & $-0,272$ & $-0,291$ & $-0,283$ \\
& $-6,506$ & $-6,583$ & $-6,403$ & $-6,446$ & $-5,369$ & $-6,434$ & $-6,241$ \\
Current EPS & $-0,0045$ & 0,0085 & 0,0011 & $-0,0054$ & 0,0063 & $-0,0009$ & $-0,0096$ \\
Indicator & $-0,759$ & 2,360 & 0,382 & $-0,769$ & 1,194 & $-0,367$ & $-1,152$ \\
Adjusted R & 0,992 & 0,992 & 0,992 & 0,992 & 0,992 & 0,992 & 0,992 \\
Log L & 533,956 & 536,680 & 533,677 & 533,916 & 534,380 & 533,644 & 534,441 \\
F test & 969,351 & 988,197 & 967,444 & 969,084 & 972,265 & 967,219 & 972,685 \\
No obs. & 285 & 285 & 285 & 285 & 285 & 285 & 285 \\
\hline
\end{tabular}




\begin{tabular}{|c|c|c|c|c|c|c|c|}
\hline & \multicolumn{9}{|c|}{ TPES/POP } \\
\hline & BL_SOX & BL_NOX & BL_NMVOC & BL_NH3 & BL_N2O & BL_CO & BL_CH4 \\
\hline $\log (\mathrm{Y} / \mathrm{P})$ & 1,846 & 1,816 & 1,845 & 1,836 & 1,591 & 1,829 & 1,808 \\
& 5,300 & 5,109 & 5,224 & 5,161 & 4,224 & 5,159 & 5,078 \\
\hline $\log (\mathrm{Y} / \mathrm{P})] 2$ & $-0,231$ & $-0,233$ & $-0,235$ & $-0,229$ & $-0,197$ & $-0,229$ & $-0,219$ \\
& $-4,217$ & $-4,214$ & $-4,225$ & $-4,104$ & $-3,383$ & $-4,139$ & $-3,895$ \\
Lagged EPS & $-0,0063$ & 0,0046 & 0,0022 & $-0,0037$ & 0,0116 & 0,0001 & $-0,0104$ \\
Indicator & $-1,239$ & 1,355 & 0,807 & $-0,672$ & 1,920 & 0,034 & $-1,502$ \\
Adjusted R & 0,992 & 0,992 & 0,992 & 0,992 & 0,992 & 0,992 & 0,992 \\
\hline Log L & 536,135 & 536,352 & 535,720 & 535,594 & 538,261 & 535,445 & 536,474 \\
\hline F test & 1019,565 & 1021,132 & 1016,583 & 1015,680 & 1035,000 & 1014,608 & 1022,011 \\
No obs. & 285 & 285 & 285 & 285 & 285 & 285 & 285 \\
\hline
\end{tabular}

\begin{tabular}{|c|c|c|c|c|c|c|c|}
\hline & \multicolumn{7}{|c|}{ TFEC/POP } \\
\hline & BL_SOX & BL_NOX & BL_NMVOC & BL_NH3 & BL_N2O & BL_CO & BL_CH4 \\
\hline $\log (\mathrm{Y} / \mathrm{P})$ & 2,275 & 2,247 & 2,279 & 2,272 & 2,145 & 2,267 & 2,250 \\
& 8,202 & 8,072 & 8,124 & 8,089 & 6,654 & 8,078 & 8,063 \\
{$[\log (\mathrm{Y} / \mathrm{P})] 2$} & $-0,302$ & $-0,306$ & $-0,306$ & $-0,300$ & $-0,284$ & $-0,301$ & $-0,294$ \\
& $-6,510$ & $-6,556$ & $-6,459$ & $-6,447$ & $-5,509$ & $-6,444$ & $-6,259$ \\
Lagged EPS & $-0,0035$ & 0,0065 & 0,0019 & $-0,0034$ & 0,0058 & $-0,0009$ & $-0,0075$ \\
Indicator & $-0,623$ & 2,063 & 0,721 & $-0,511$ & 1,139 & $-0,347$ & $-0,944$ \\
Adjusted R & 0,992 & 0,993 & 0,992 & 0,992 & 0,992 & 0,992 & 0,992 \\
\hline Log L & 546,015 & 547,714 & 546,004 & 545,923 & 546,557 & 545,823 & 546,355 \\
\hline F test & 1034,133 & 1046,619 & 1034,054 & 1033,462 & 1038,103 & 1032,733 & 1036,619 \\
No obs. & 285 & 285 & 285 & 285 & 285 & 285 & 285 \\
\hline
\end{tabular}

Notes: see notes to Table 4 in main text. 